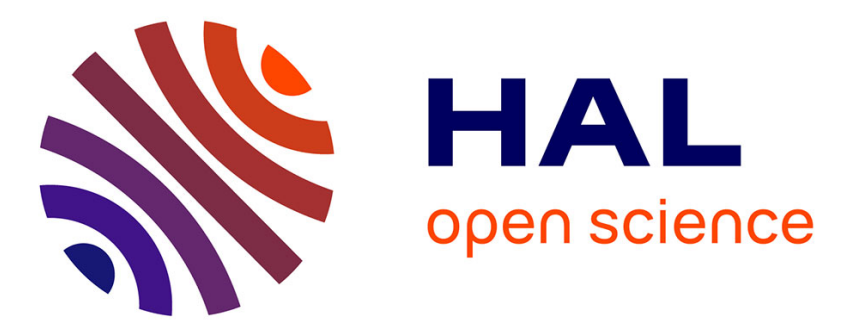

\title{
Mineralogy of the Nili Fossae region with OMEGA/Mars Express data: 2. Aqueous alteration of the crust
}

N. Mangold, F. Poulet, J.-F. Mustard, J.-P. Bibring, B. Gondet, Y. Langevin, V. Ansan, Ph. Masson, C. Fassett, J.-W. Head, et al.

\section{- To cite this version:}

N. Mangold, F. Poulet, J.-F. Mustard, J.-P. Bibring, B. Gondet, et al.. Mineralogy of the Nili Fossae region with OMEGA/Mars Express data: 2. Aqueous alteration of the crust. Journal of Geophysical Research. Planets, 2007, 112, pp.E08s04. hal-00376813

\section{HAL Id: hal-00376813 https://hal.science/hal-00376813}

Submitted on 22 Sep 2021

HAL is a multi-disciplinary open access archive for the deposit and dissemination of scientific research documents, whether they are published or not. The documents may come from teaching and research institutions in France or abroad, or from public or private research centers.
L'archive ouverte pluridisciplinaire $\mathbf{H A L}$, est destinée au dépôt et à la diffusion de documents scientifiques de niveau recherche, publiés ou non, émanant des établissements d'enseignement et de recherche français ou étrangers, des laboratoires publics ou privés.

$$
\text { Copyright }
$$




\title{
Mineralogy of the Nili Fossae region with OMEGA/Mars Express data:
}

\section{Aqueous alteration of the crust}

\author{
N. Mangold, ${ }^{1}$ F. Poulet, ${ }^{2}$ J. F. Mustard, ${ }^{3}$ J.-P. Bibring, ${ }^{2}$ B. Gondet,${ }^{2}$ Y. Langevin, ${ }^{2}$ \\ V. Ansan, ${ }^{1}$ Ph. Masson, ${ }^{1}$ C. Fassett, ${ }^{3}$ J. W. Head III, ${ }^{3}$ H. Hoffmann, ${ }^{4}$ and G. Neukum ${ }^{5}$ \\ Received 26 September 2006; revised 25 January 2007; accepted 6 March 2007; published 4 August 2007.
}

[1] Nili Fossae is a region with fresh exposures of old material. OMEGA spectral data have revealed a strong diversity of minerals in the Nili Fossae region, including mafic minerals and phyllosilicates. Phyllosilicates are found to be primarily Fe-rich smectites (a type of clay minerals). These phyllosilicates are observed only on the Noachian crust, in four types of locations: Three are without any signatures other than phyllosilicates, on (1) smooth layered deposits, (2) massive exhumed material, and (3) crater ejecta, and one type of location is associated with olivine (4) over an altered mafic unit. This diversity suggests a widespread liquid water activity and a variety of alteration processes. The formation of phyllosilicates underwent considerable reduction, if not cessation, by the time of formation of Syrtis Major lava flows in the Hesperian period. Phyllosilicates are spatially and chronologically disconnected from the fluvial and depositional landforms observed in the Nili Fossae region. Observations suggest that these landforms formed after the extensive formation of phyllosilicates during short periods of time and/or temperatures close to freezing.

Citation: Mangold, N., et al. (2007), Mineralogy of the Nili Fossae region with OMEGA/Mars Express data: 2. Aqueous alteration of the crust, J. Geophys. Res., 112, E08S04, doi:10.1029/2006JE002835.

\section{Introduction}

[2] The Nili Fossae region is located north of the Syrtis Major volcanic complex in the Northeastern hemisphere of Mars (Figure 1). This part of Mars has been known as a geologically interesting region for volcanic studies for a long time [e.g., Schaber, 1982], and it has been the subject of increasing interest since the discovery of olivine exposures by the Thermal Emission Spectrometer (TES) on board Mars Global Surveyor (MGS) [Christensen et al., 2001; Hoefen et al., 2003; Hamilton and Christensen, 2005; Martínez-Alonso et al., 2006]. The OMEGA (Observatoire pour la Minéralogie, l'Eau, les Glaces et l'Activité) spectrometer on board Mars Express (MEx) has detected the presence of abundant areas with phyllosilicates in this region [Bibring et al., 2005; Poulet et al., 2005]. In these first studies, most phyllosilicates in the Nili Fossae region appeared to have been restricted to the Noachian outcrops, with possible exception of dark spots located to the north

\footnotetext{
${ }^{1}$ Laboratoire IDES, UMR8148 CNRS and Université Paris-Sud, Orsay, France.

${ }^{2}$ Institut d'Astrophysique Spatiale, CNRS/Université Paris-Sud, Orsay, France.

${ }^{3}$ Department of Geological Sciences, Brown University, Providence, Rhode Island, USA.

${ }^{4}$ Institut für Weltraumsensorik, DLR, Berlin, Germany.

${ }^{5}$ Institut für Geologische Wissenschaften, Freie Universität Berlin, Berlin, Germany.
}

Copyright 2007 by the American Geophysical Union. 0148-0227/07/2006JE002835
[Poulet et al., 2005]. We will not discuss the presence of these dark hydrated spots and we restricted our study of hydrated materials in the Nili Fossae region to latitudes between 15 and $23^{\circ} \mathrm{N}$. Mafic minerals such as olivine and pyroxenes have also been detected in OMEGA data [Mustard et al., 2005]. The detection and mapping of these minerals are carefully analyzed in a companion paper [Mustard et al., 2007].

[3] The overall geology of the region can be seen from a MOC wide-angle image (Figure 1). Two main units are present: Noachian highlands and lava plains. To the south, Syrtis Major Planum is a volcanic plain dated at the end of the Early Hesperian [Hiesinger and Head, 2004]. The NE-SW straight lineations of Nili Fossae correspond to tectonic graben due to major faults likely in relation to the Isidis impact basin [Wichman and Schultz, 1989; Kraal et al., 1998]. These features cross the Noachian terrains but do not cross the Hesperian plains, thus predating the last episodes of Syrtis Major lava flows. The largest trough system, which is named Nili Fossae, displays a flat floor interpreted to be filled by Syrtis lava flows [Hiesinger and Head, 2004] dominated by pyroxenes [Mustard et al., 2005]. The Nili Fossae region is thus a complex area requiring detailed geologic analysis for a better understanding of the spectral data. In this study, we have combined OMEGA spectral data with images from MEx/HRSC (High Resolution Stereo Camera) and other camera systems as Mars Observer Camera (MOC) and THEMIS (Thermal Emission Imaging 

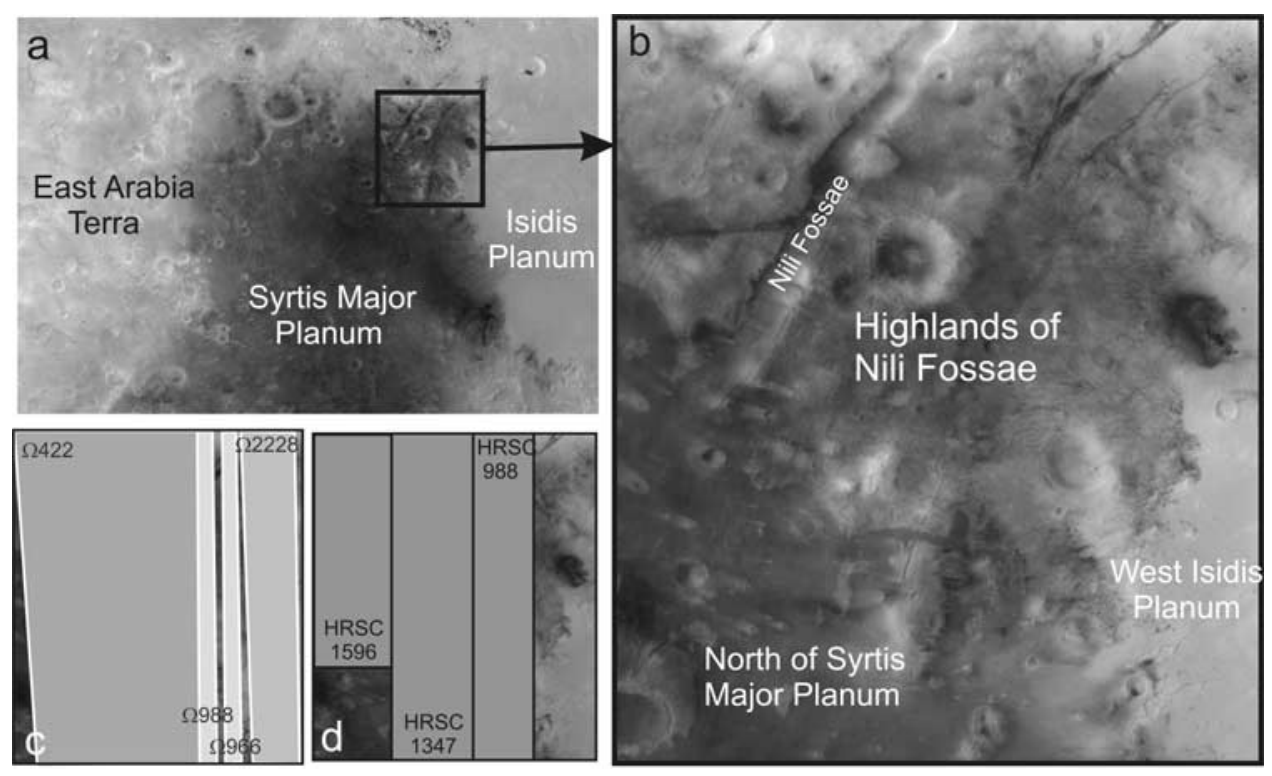

Figure 1. (a) MOC wide-angle image (MC13 quadrangle) of the Nili Fossae region. (b) The Nili Fossae low-albedo region. (c) OMEGA and (d) HRSC data analyzed with orbit numbers (same region as in Figure $1 \mathrm{~b}$ for both Figures $1 \mathrm{c}$ and $1 \mathrm{~d})$.

System) to describe the primary geomorphic features and geologic units.

\section{Mars Express Data and Other Data Sets Used}

[4] The OMEGA instrument acquires image cubes in a wavelength domain $(0.35$ to $5.1 \mu \mathrm{m})$ dominated by solar reflected light below $2.6 \mu \mathrm{m}$ with a spectral sampling of $14 \mathrm{~nm} / \mathrm{spectel}$ and a spatial sampling varying from a few kilometers to a few hundred meters depending on the spacecraft altitude. The Near InfraRed (NIR) part of the instrument consists in two spectrometers: a Short Wavelength IR channel (SWIR, 0.93-2.7 $\mu \mathrm{m}$ ) and a Long Wavelength IR channel (LWIR, 2.6-5.1 $\mu \mathrm{m}$ ). Several OMEGA orbits of low and high spatial resolutions cover the whole Nili Fossae-Syrtis Major region. Orbits 422 ( $\sim 1.2 \mathrm{~km} /$ pixel), 966 and $988(\sim 300 \mathrm{~m} /$ pixel $)$, and 2228 ( $\sim 600 \mathrm{~m} /$ pixel) were used in this study. Note that some spectels in the 988 and 2228 observations were damaged because of a degradation of the IR detector.

[5] OMEGA reflectance spectra contain both atmospheric and surface components. Dust, $\mathrm{CO}_{2}, \mathrm{CO}, \mathrm{H}_{2} \mathrm{O}$ (vapor, ice) signatures are often present in the spectra. It is therefore essential to remove the spectral effects of the atmospheric constituents. Assuming a constant surface contribution, the ratio of a spectrum from the base of Olympus Mons to one over the summit provides the atmospheric transmission spectrum at a power function of their difference in altitude. The atmospheric contribution to each spectrum is then removed by dividing the observation by the derived atmospheric spectrum, scaled by the strength of the $\mathrm{CO}_{2}$ atmospheric absorption measured in the observation. Using this standard processing technique for removing the atmospheric gas absorptions for each pixel [Bibring et al., 2005; Mustard et al., 2007], it has been shown that unambiguous signatures of mafic minerals (pyroxene and olivine) and hydrated minerals (sulfates, phyllosilicates) can be identified in the 1-2.5 $\mu \mathrm{m}$ wavelength range [Mustard et al., 2005; Gendrin et al., 2005; Poulet et al., 2005]. The reflectance spectra are divided by the cosine of the incidence angle assuming a Lambertian surface, so that the spectra are labeled Lambertian albedo.

[6] The spectrum ratio method has also been applied to make a cautious interpretation of surface mineralogy detected by OMEGA. We select an average spectrum from an area of similar albedo and altimetry extracted from the same OMEGA cube than the region of interest, then divide the spectrum of interest by the average spectrum. This results in an atmospherically (both atmosphere and dust) and instrumentally corrected (systematic noise) ratioed spectrum. This technique is very efficient to emphasize the surface spectral features, and has been used in numerous previous analyses of the OMEGA data [Mustard et al., 2005; Gendrin et al., 2005; Poulet et al., 2005]. In addition, the random noise has been studied and can produce artificial band depth but always smaller than $2 \%$ that is the minimum threshold of detection for all the minerals discussed in this paper (Table 1).

Table 1. Spectral Parameters Used to Detect Olivine and Hydrated Minerals

\begin{tabular}{llcl}
\hline \multicolumn{1}{c}{ Name } & \multicolumn{1}{c}{ Formulation } & Detection Threshold & \multicolumn{1}{c}{ Rationale } \\
\hline Olivine & $(0.5 * \mathrm{R}(1.69)+0.5 * \mathrm{R}(1.70)) /$ & 1.02 & $1 \mu \mathrm{m}$ band due to Olivine \\
& $(0.1 * \mathrm{R}(1.01)+0.1 * \mathrm{R}(1.21)+$ & & \\
$1.9 \mu \mathrm{m}$ band depth & $\left.0.4 * \mathrm{R}(1.36)+0.4^{*} \mathrm{R}(1.50)\right)$ & & \\
$2.30 \mu \mathrm{m}$ band depth & $1-\mathrm{R}(1.93) /(0.5 * \mathrm{R}(1.80)+0.5 * \mathrm{R}(2.12))$ & 0.02 & $\mathrm{H}_{2} \mathrm{O}$-bearing minerals \\
& $(0.25 * \mathrm{R}(2.26)+0.25 * \mathrm{R}(2.27)+0.5 * \mathrm{R}(2.34))$ & 0.02 & $\begin{array}{l}\text { Metal-OH feature indicator of } \\
\text { Fe/Mg-rich clays }\end{array}$ \\
\hline
\end{tabular}


[7] MEx/HRSC data used consists of the nadir and stereo images which allow calculation of Digital Elevation Models (DEM). The nadir image has the highest resolution possible from the camera performance and the elliptical orbit characteristics, usually varying from about $12 \mathrm{~m}$ at the pericenter to about 20 to $30 \mathrm{~m} / \mathrm{pixel}$ at image upper and lower edges. Stereo images are obtained at spatial sampling 2 or 4 times degraded from the initial nadir resolution. Orbits 988, 1347 and 1596 are used in this study with nadir image sampling between 15 and 25 meters. A mosaic of the three images has been completed at $25 \mathrm{~m} /$ pixel in the region of interest. DEMs of each of the orbits have been computed using tools developed for the HRSC instrument [Gwinner et $a l ., 2005]$ in order to improve the geologic interpretation. DEMs have spatial sampling of $50 \mathrm{~m}$ and a vertical accuracy of $54 \mathrm{~m}$ for orbit $988,37 \mathrm{~m}$ for orbit 1347 and $41 \mathrm{~m}$ for orbit 1596 . We also used the color image of orbit 988 which is a combination of data taken with red, green and blue filters. The tracks of HRSC and OMEGA data have been plotted on the MGS/MOC wide-angle map for context (Figure 1).

[8] Additional data include Odyssey/THEMIS visible images [Christensen et al., 2003] at $18 \mathrm{~m} / \mathrm{pixel}$ and MOC narrow angle images at $2.8 \mathrm{~m} /$ pixel [Malin and Edgett, 2000, 2001]. All of these data are referenced with a GIS software under the IAU2000 planetocentric system. Small differences $(<2 \mathrm{~km})$ in coordinates are possible when combining data from different orbiters. We compared distinct locations from HRSC images, OMEGA NIR albedo and MOLA topography to validate the consistency of data under the same referencing system. For MOC images, we preferred not to project images automatically, and tiepointed these images into HRSC or THEMIS visible images, thanks to the gap of resolution which is low and enable us to clearly see the main features visible in both data sets. This method provides the possibility to compare morphology at the scale of OMEGA highest spatial sampling $(300 \mathrm{~m})$.

\section{Mineralogical Identification and Mapping With OMEGA}

\subsection{Mafic Minerals}

[9] Pyroxene-rich rocks are present in this region for which a detailed mapping in terms of identification and geological context is given in the companion paper [Mustard et al., 2007]. When present, both high-calcium pyroxenes (HCP) and low-calcium pyroxenes (LCP) are detected with a varying relative proportion [Mustard et al., 2007]. On the Syrtis lava flows, HCP dominates, whereas the Noachian crust contains LCP too [Mustard et al., 2005]. Olivine is identified through its unique, spectrally broad and strong Fe absorption throughout the $0.8-1.8 \mu \mathrm{m}$ range. An olivine spectral index similar to that considered in the companion paper [Mustard et al., 2007] and carefully presented by Poulet et al. [2007] is used here (Table 1) in order to map its spatial distribution and to compare it with the spatial distribution of phyllosilicates.

\subsection{Phyllosilicates}

[10] The presence of the water molecule can be made with the $1.9 \mu \mathrm{m}$ and $3 \mu \mathrm{m}$ bands resulting from the over- tones and the combinations of fundamental vibrations of $\mathrm{H}_{2} \mathrm{O}$ and $\mathrm{OH}$. All OMEGA spectra exhibit a strong $3 \mu \mathrm{m}$ feature which is attributed to the presence of adsorbed water and/or confined water [Bibring et al., 2005; Jouglet et al., 2007]. The $\sim 1.9 \mu \mathrm{m}$ feature can be associated with adsorbed/trapped water or hydrated minerals (hydrous salts, hydrous phyllosilicates, hydrous hydroxides). The intensity of this feature is much weaker than the $3 \mu \mathrm{m}$ band, and is commonly due to the combination of the asymmetric $\mathrm{OH}$ stretch modes and $\mathrm{H}-\mathrm{O}-\mathrm{H}$ bend in the case of phyllosilicates or water molecules vibrations in sulfate lattices for instance. Experimental tests show that the $\sim 1.9 \mu \mathrm{m}$ absorption is dependent on how water is held in the mineral structure [Milliken and Mustard, 2005]. This feature has been detected in a very few specific regions on Mars so far [Bibring et al., 2006] and is associated in many cases with other features in the $2.1-2.5 \mu \mathrm{m}$ range indicating the presence of phyllosilicates and/or sulfates. Therefore, in the very dry Martian conditions, the $1.9 \mu \mathrm{m}$ feature has been interpreted as an indicator of water in the structure of minerals rather than adsorbed/trapped water. A spectral index was developed that measures the depth of the absorption at $1.93 \mu \mathrm{m}$ relative to the continuum defined at 1.80 and $2.12 \mu \mathrm{m}$ (Table 1). The detection is considered positive for a value of the spectral index larger than 0.02 , with exception of the low-resolution orbit 422 where 0.03 has been used as minimum for robustness of the detection.

[11] Other spectral features typical of hydrous minerals occur at $\sim 1.4 \mu \mathrm{m}$ which is produced by the first overtone of the hydroxyl group stretch and combinations of the $\mathrm{H}_{2} \mathrm{O}$ bend, while the features in the $2.2-2.4 \mu \mathrm{m}$ range are due to combination overtones of metal-OH groups and bend modes. The $\sim 1.4 \mu \mathrm{m}$ band is weaker than the $\sim 1.9 \mu \mathrm{m}$ one, so this band is not used for mapping. The identification of metal-OH features combined with the $\sim 1.9 \mu \mathrm{m}$ signature is a robust indicator of the presence of Fe-rich and $\mathrm{Mg}$-rich smectites [e.g., Poulet et al., 2005]. In laboratory spectra, spectral features centered at 2.29-2.3 $\mu \mathrm{m}$ and $2.34 \mu \mathrm{m}$ are diagnostic of $\mathrm{Fe}-\mathrm{OH}$ and $\mathrm{Mg}-\mathrm{OH}$ vibrations, respectively; mixture of both bands is also found. Therefore, once hydrous minerals are identified using the $\sim 1.9 \mu \mathrm{m}$ band, the spectral analysis is focused on the $2.2-2.4 \mu \mathrm{m}$ interval (Figure 2). Figures 2 and 3 show spectra collected over different areas discussed in the next sections where the metal-OH bands are mainly centered at 2.29 to $2.31 \mu \mathrm{m}$. No strong feature has been unambiguously identified in this region due to single $\mathrm{Mg}-\mathrm{OH}$ (at $2.34 \mu \mathrm{m}$ ), or to $\mathrm{Al}-\mathrm{OH}$ (at $2.20 \mu \mathrm{m})$. No feature at $2.4 \mu \mathrm{m}$ indicative of sulfates has been detected in this region so far.

[12] A spectral index using the absorption band centered near $2.30 \mu \mathrm{m}$ was defined (Table 1). This index has typical values varying between -0.010 and +0.015 due to random noise of the instrument. A threshold of 0.02 was therefore used in order to be above baseline values to validate the detection. The spatial distributions of the spectral signatures reveal that the $\sim 2.3 \mu \mathrm{m}$ band, when detected, is correlated with the hydration band at $\sim 1.9 \mu \mathrm{m}$ on the overall maps (Figures 4, 5, and 6). This spatial correlation is especially visible in the red-blue composition of Figure 5 in the purple colored pixels, with the detection of the $\sim 2.3 \mu \mathrm{m}$ band less widespread than the $\sim 1.9 \mu \mathrm{m}$. The $\sim 2.3 \mu \mathrm{m}$ band is probably not mapped as well as the $\sim 1.9 \mu \mathrm{m}$ band due to 

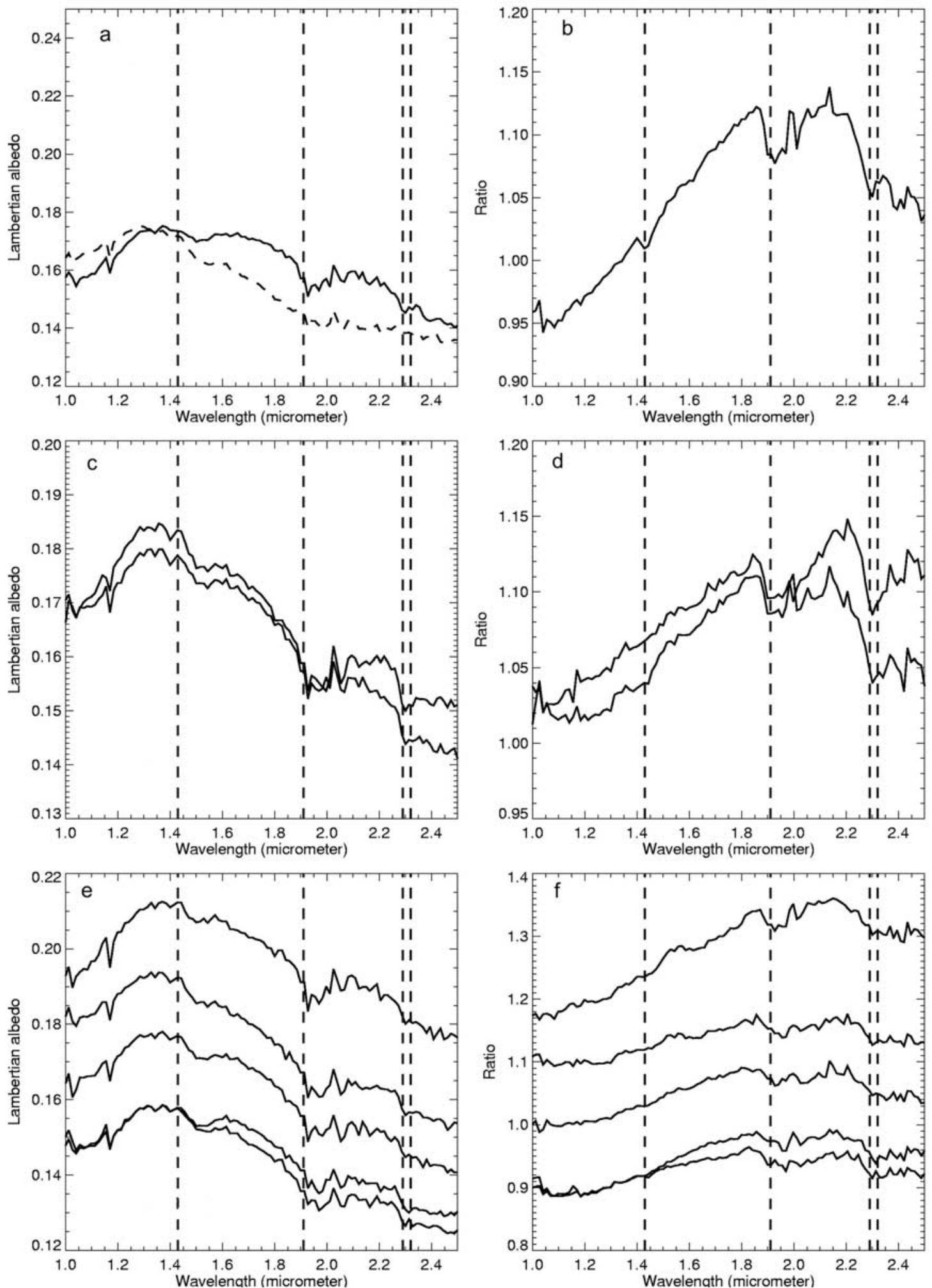

Figure 2. Identification of phyllosilicates over the Nili Fossae region. Each spectrum corresponds to a single OMEGA pixel. Left column: Reflectance spectra of the regions studied in Figure 9a, Figure 10c, 11, and 12e. Right column: Figures $2 \mathrm{~b}, 2 \mathrm{~d}$, and $2 \mathrm{f}$ are ratios calculated using the reference spectrum plotted with dashed lines in Figures 2a, 2c, and 2e, respectively. Vertical dashed lines correspond to absorption bands at $\sim 1.4, \sim 1.9$, and $\sim 2.3 \mu$ m which are diagnostic of Fe-rich smectites. In Figure 2e the $\sim 2.3 \mu \mathrm{m}$ feature has a plateau shape rather than a distinct band. 

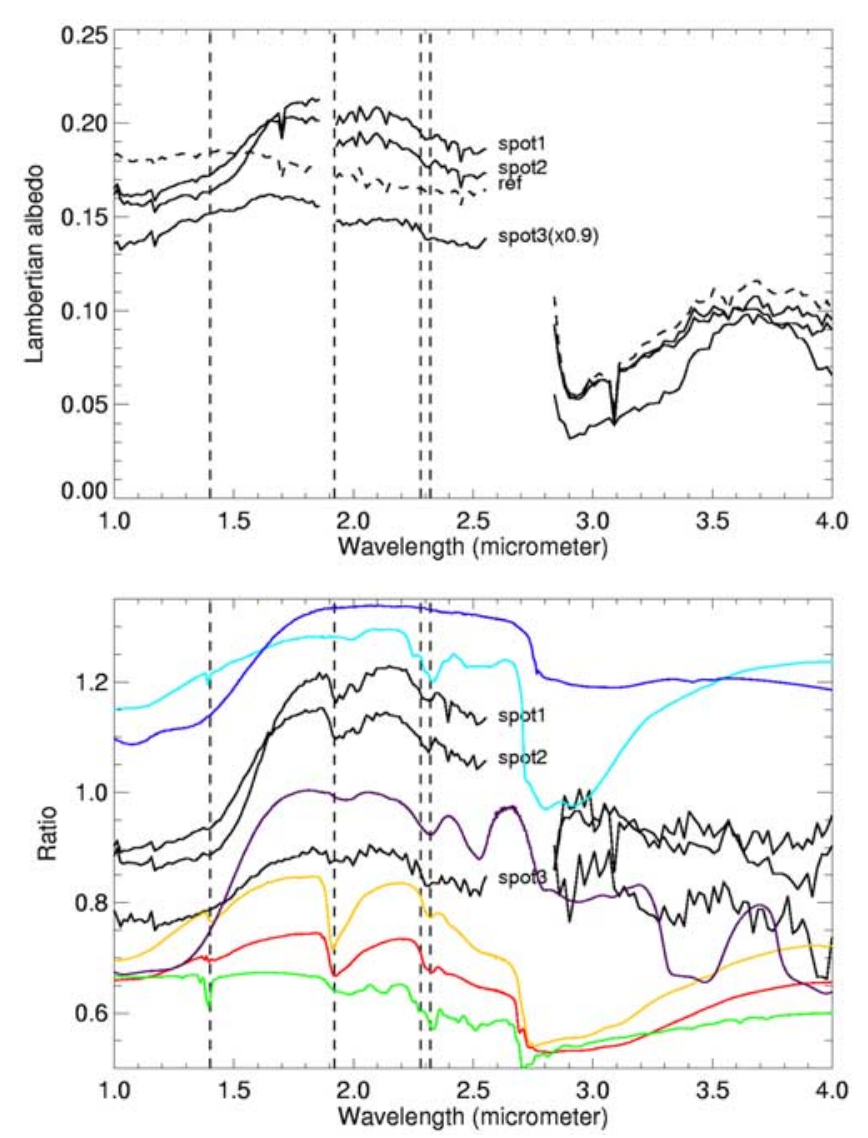

Figure 3. Spectra of olivine with bands of hydrous minerals. (top) Spectra extracted from spots 1, 2, and 3 (see Figure 4 for localization) show a strong band at 1 to $1.5 \mu \mathrm{m}$ attributed to olivine as well as ones at 1.9 and $2.3 \mu \mathrm{m}$ that are diagnostic of phyllosilicates. The spectrum in dashed line is the reference used for ratios. Each spectrum corresponds to a single OMEGA pixel. The spectra between 1.89 and $1.92 \mu \mathrm{m}$ are not plotted because of the instrumental artifacts that are removed by using the spectral ratio technique. (bottom) Spectral ratios (spots/reference) compared to laboratory spectra of olivine (dark blue), chlorite (light blue), siderite (violet), saponite (yellow), vermiculite (red), and serpentine (green). The vertical dashed lines indicate the positions of the major features associated to the phyllosilicates as discussed in the text. The gap between 2.6 and $2.9 \mu \mathrm{m}$ is due to saturated atmospheric bands due to $\mathrm{CO}_{2}$. The signal to noise is lower in the 2.9-4.0 $\mu \mathrm{m}$ interval (L channel of OMEGA) than in the 1.0-2.6 $\mu \mathrm{m}$ interval (C channel of OMEGA).

the smaller strengths of the metal-OH band, as observed in laboratory spectra [Clark et al., 1993], and/or a small difference in composition. This supports the idea that the pixels with the single band at $\sim 1.9 \mu \mathrm{m}$, when located surrounding a $2.3 \mu \mathrm{m}+1.9 \mu \mathrm{m}$ area, may consist of similar materials. Alternatively, this might be hydrous material altered simultaneously with slight variations in composition due to processes such as chemical zonation.

[13] Many spectra that do not have a well identified $\sim 2.3 \mu \mathrm{m}$ band display a plateau-like right wing starting at $\sim 2.3 \mu \mathrm{m}$ band (Figures $2 \mathrm{e}$ and $2 \mathrm{f}$ ). Such a spectral feature is commonly observed for minerals containing all the cations $\mathrm{Fe}, \mathrm{Mg}$ and/or Al typical of various phyllosilicates such as corrensite, vermiculite and chlorite [Clark et al., 1993]. Some spectra of talc and saponite also exhibit this spectra characteristic [Clark et al., 1993]. In a few locations the $\sim 1.9 \mu \mathrm{m}$ band is identified without any metal-OH band or plateau shape at $\sim 2.3 \mu \mathrm{m}$; the detection can correspond to any hydrous minerals. Additionally, in some locations (Figure 6 ), the $\sim 2.3 \mu \mathrm{m}$ band exists without a distinct $\sim 1.9 \mu \mathrm{m}$ band; this may be a result of dehydration of phyllosilicates [Milliken and Mustard, 2005] or of the presence of other minerals. This specific case is not further discussed in this study.

[14] In summary, we distinguish two types of phyllosilicates: (1) smectites identified with both a $\sim 1.9 \mu \mathrm{m}$ hydration band and the $\sim 2.3 \mu \mathrm{m}$ metal-OH band and (2) undetermined phyllosilicates (such as smectites, chlorites, vermiculites or talc) with the $\sim 1.9 \mu \mathrm{m}$ band and the $\sim 2.3 \mu \mathrm{m}$ plateau shape. Another type of mineral corresponds to undetermined hydrous minerals mapped with the single $\sim 1.9 \mu \mathrm{m}$ signature in regions devoid of metal$\mathrm{OH}$ signatures.

\subsection{Hydration Bands Mixed With Olivine Signatures}

[15] Of particular interest are the regions where the hydrous signatures are observed in association with the olivine signature in the $1.0-1.5 \mu \mathrm{m}$ range (Figure 3 ). The spectra of these areas indeed exhibit both very strong olivine shape and $\sim 1.9 \mu \mathrm{m}$ bands as well as a feature at $\sim 2.3 \mu \mathrm{m}$ with its maximum depth at approximately $2.31 \mu \mathrm{m}$ (Figure 3, bottom). This shift to a longer wavelength relative to the feature at $2.29 \mu \mathrm{m}$ of the spectra shown in Figure 2 suggests slightly more Mg-rich than Fe-rich composition. These distinct spectral and unique characteristics are currently well identified in three spots only: spot 1 centered at $78.6^{\circ} \mathrm{E}$, $21.9^{\circ} \mathrm{N}$, spot 2 centered at $78.6^{\circ} \mathrm{E}, 20.4^{\circ} \mathrm{N}$, spot 3 centered at $77.15^{\circ} \mathrm{E}, 17.25^{\circ} \mathrm{N}$ (Figure 4).

[16] The comparison of these spectra with a suite of laboratory spectra is shown in Figure 3. Initial alteration products of olivine, or olivine-bearing rocks, usually consist of iddingsite (mixtures of various smectites and oxides [e.g., Chesworth et al., 2004]) or minerals from the serpentine group, depending on temperature, oxidation conditions, and Mg-ions mobility [e.g., Righi and Meunier, 1995]. Although this comparison is limited by the available laboratory spectra [Clark et al., 1993], none of these fits the OMEGA spectra. Serpentine library spectra are usually Mg-rich serpentine with features at $2.34 \mu \mathrm{m}$ rather than around $2.30 \mu \mathrm{m}$ not excluding Fe-rich serpentine to have features at $2.31 \mu \mathrm{m}$. Stronger alteration of olivine-bearing rocks can lead to the formation of various phyllosilicates such as smectites (saponite, nontronite) or vermiculites [e.g., Righi and Meunier, 1995], but the signatures of these minerals do not fit the strong $\mathrm{Fe}^{2+}$ band in the $1.0-1.5 \mu \mathrm{m}$ range (Figure 3). Additionally, the iron carbonate mineral siderite provides a reasonable fit in the $1.0-2.5 \mu \mathrm{m}$ range, but this mineral can be ruled out because the Mars spectra do not show the typical and very strong feature at $3.4 \mu \mathrm{m}$ due to vibrational modes in $\mathrm{CO}_{3}^{-2}$. Thus we do not focus on the identification of specific olivine alteration minerals but instead concentrate on the association of signatures typical of olivine and phyllosilicates, not excluding the possibility 


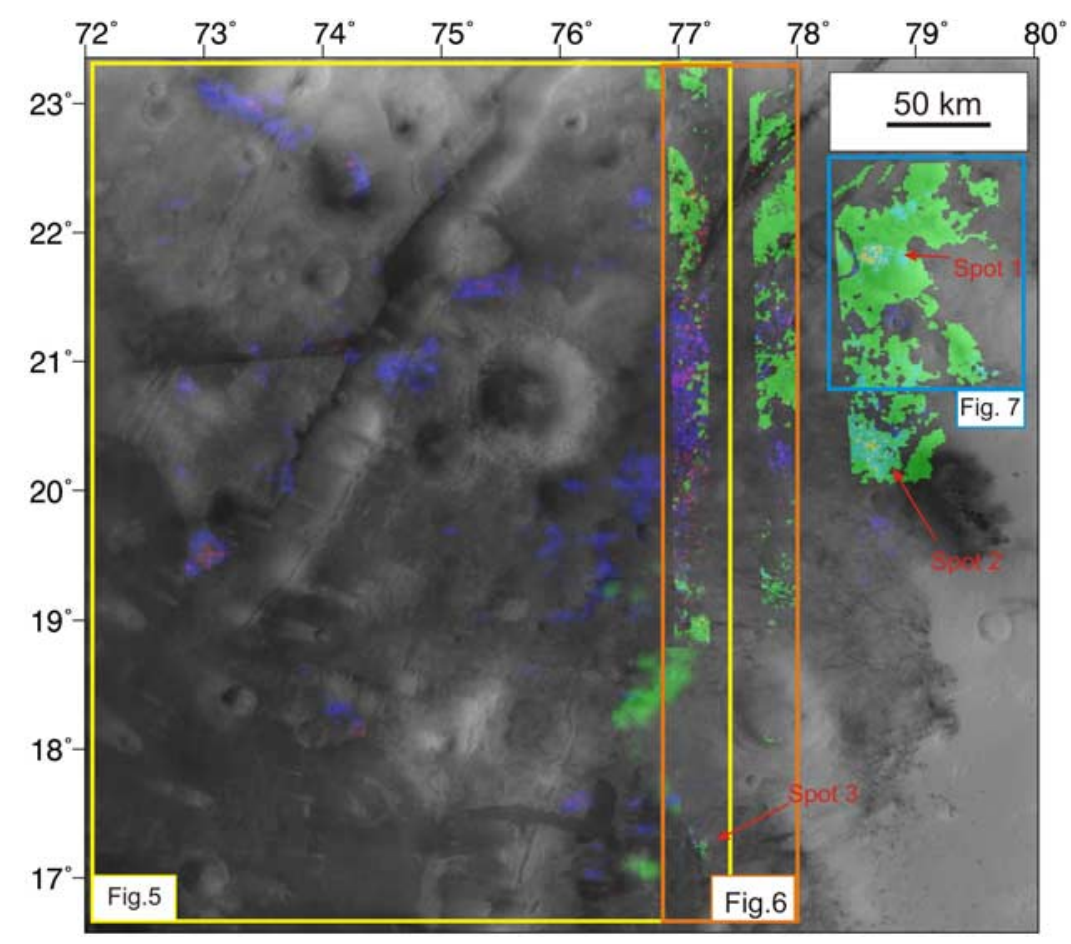

Figure 4. OMEGA map of hydration band ( $\sim 1.9 \mu \mathrm{m}$ in blue), Fe-OH band ( $2.3 \mu \mathrm{m}$ in red), and olivine (in green) mapped over MOC wide-angle. Fe-OH bands are coupled to hydration bands in the same locations. The eastern side exhibits larger values of the spectral parameter of olivine that can be due to larger grain size or larger abundance. Spots 1 to 3 show areas with the three signatures (yellow pixels). Color rectangles show locations of the corresponding figure number. Projection is sinusoidal with the $75 \mathrm{E}$ longitude as reference.

of a single mineral such as iron-rich serpentine. If the spectra correspond to a detection of two minerals, they are mixed together either by subpixel mixing of olivine and hydrous minerals in different geologic units or by microscopic mixing of both minerals in the same unit.

\subsection{Mapping}

[17] Maps derived from OMEGA results have been made into two types of figures: independent bands with color scale representing the band depths (as listed in Table 1) and RGB maps using the $\sim 2.3 \mu \mathrm{m}$ band as red, the $\sim 1.9 \mu \mathrm{m}$ band as blue and olivine as green (Figures 4 to 7). The two types of figures are used together for interpretation. Mineral abundances are not reported here because the strength of each spectral index depends on a variety of parameters such as the mineral mixture, the relative concentration, the optical constants and the grain size distribution of each mineral, the surface texture and the atmospheric condition. Moreover, mineral deconvolution using complex radiative transfer theory that is necessary to provide concentrations is very time-consuming and requires optical constants of minerals that are not known especially for the clays. At a first approximation, we assume that the spectral parameters can be related to the abundance and/or the grain size. The larger the spectral parameter is, the larger the abundance is, or the larger the grain size is.

[18] All RGB maps are plotted over the MOC wide-angle mosaic of the region (Figure 4). This map shows that the western part of the region, mostly on the OMEGA orbit 422 , displays lot of hydrous signatures which do not coincide spatially with olivine deposits. The eastern part displays hydrous signatures with the $\sim 1.9 \mu \mathrm{m}$ band closely related to olivine deposits, and locally superimposed on the three spots as mentioned previously. More synoptic regional views can be seen on the HRSC images (Figure 5). For a closer view of OMEGA narrow orbits 988 and 966 we have plotted them separately (Figure 6). For this figure, it was also interesting to compare the result with the HRSC color image. OMEGA detects hydrous minerals and olivine in the relative dark areas of this color image whether the brighter reddish parts of the image are devoid of signatures, thus suggesting the effect of local surface dust that limits the detection. Finally, on the eastern side, we used a mosaic of THEMIS visible images (Figure 7). Olivine is spatially decoupled from hydration bands in most locations where the two are detected (Figure 6), but they are often coupled in the same pixels where turquoise color (olivine with hydration band) or even orange color (olivine with both $\sim 1.9 \mu \mathrm{m}$ and $\sim 2.3 \mu \mathrm{m}$ band) is detected (spots 1 to 3 in Figure 4). As there was no high-resolution visible image available on the spot 2, we limited the geologic study to spots 1 and 3 .

\section{Correlation Between Hydrous Minerals and Landforms}

[19] Correlation of hydrous minerals with geology is necessary to have a better understanding of the origin of these minerals. In this section, we first study the correlation of the hydrous minerals with all types of landforms and 


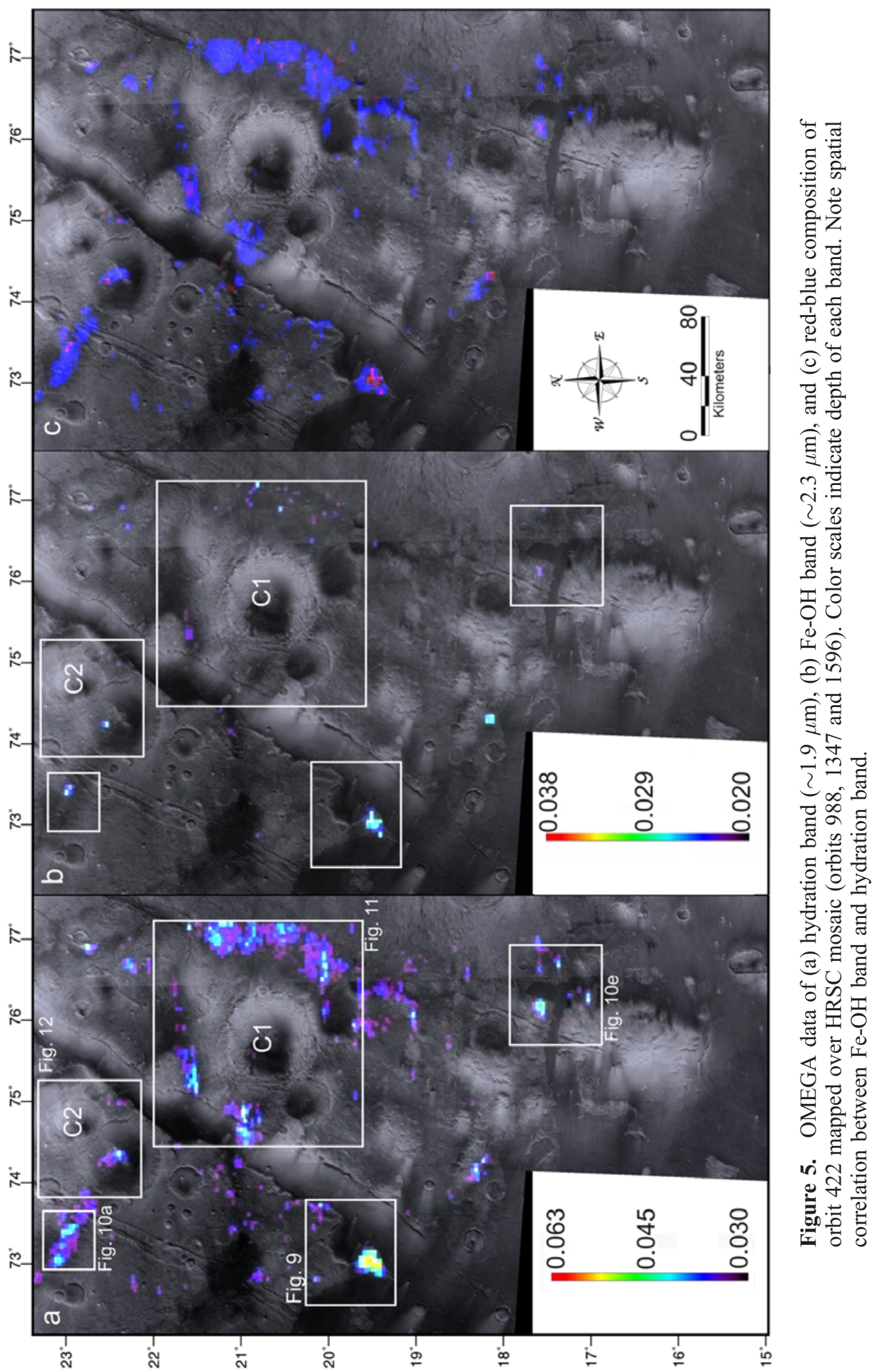




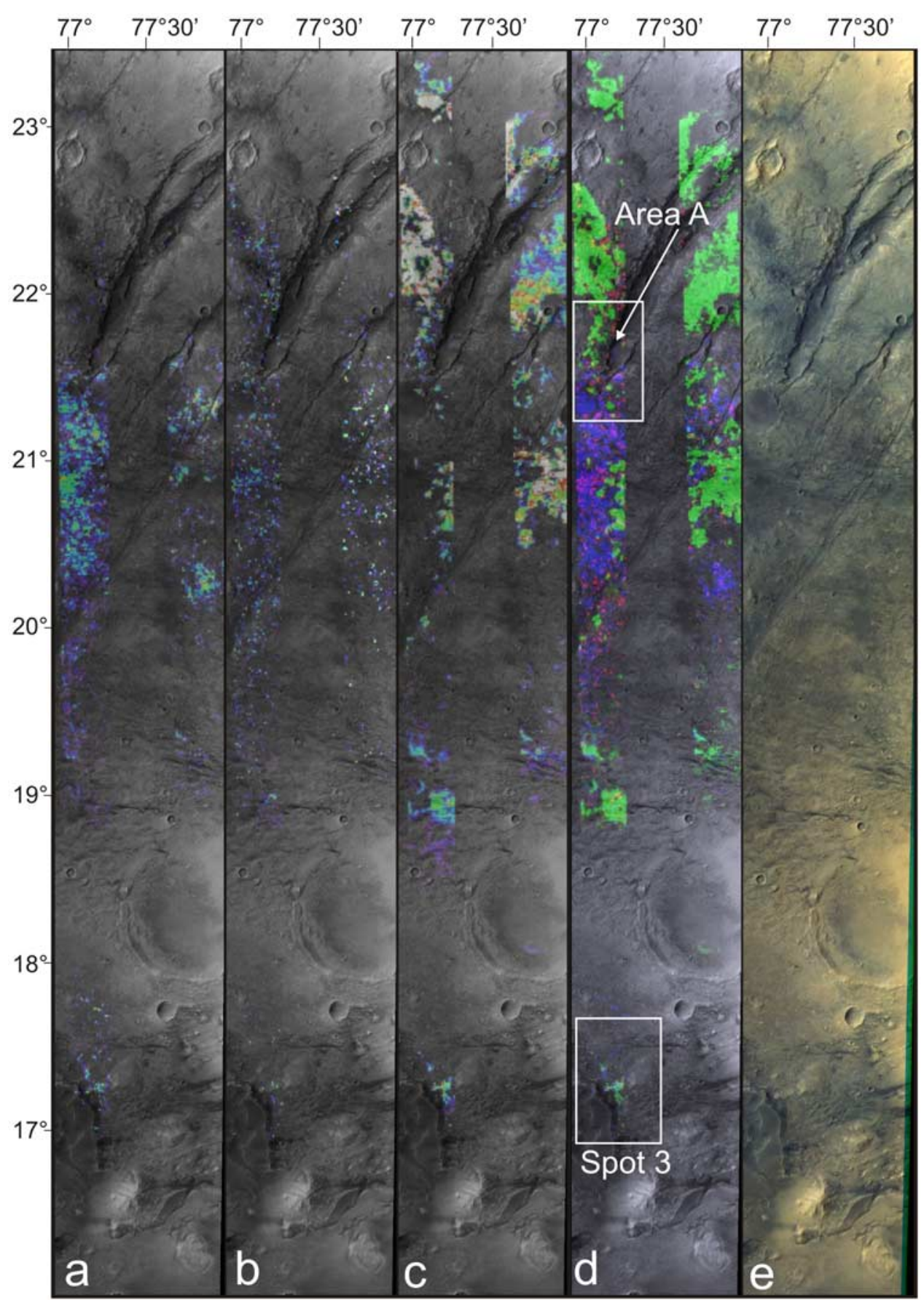

Figure 6. OMEGA data of orbits 988 and 966 mapped over HRSC image 988: (a) 1.9 $\mu$ m band with absorption depth from 0.02 (blue) to 0.05 (red), (b) $\sim 2.3 \mu \mathrm{m}$ band from 0.02 (blue) to 0.04 (red), (c) olivine from 1.02 (blue) to 1.15 (white), (d) RGB map as in Figure 4, and (e) HRSC color image. Area A shows a location with olivine close to hydrous minerals (see Figure 15). Hydration and olivine are close but not mixed in the same pixel except for spot 3. OMEGA detects minerals in the dark locations, whereas bright reddish locations in Figure 6e have no signatures.

main geologic units, and in the following section we study their relationship to the olivine occurrences.

\subsection{Exhumation of Crustal Outcrops}

[20] The overall surface morphology of the region can be seen from the HRSC data (Figures 5 and 8). Figure 8 displays a simplified geologic map made from HRSC images which is useful to identify the main landforms and the Nili Fossae floor. The map is based on units defined in the geological map by Greeley and Guest [1987]. Hydrous minerals are detected in different areas of the studied region, but mainly on outcrops of the Noachian highlands (Figure 5 and Figure 8). The three following examples are outcrops 


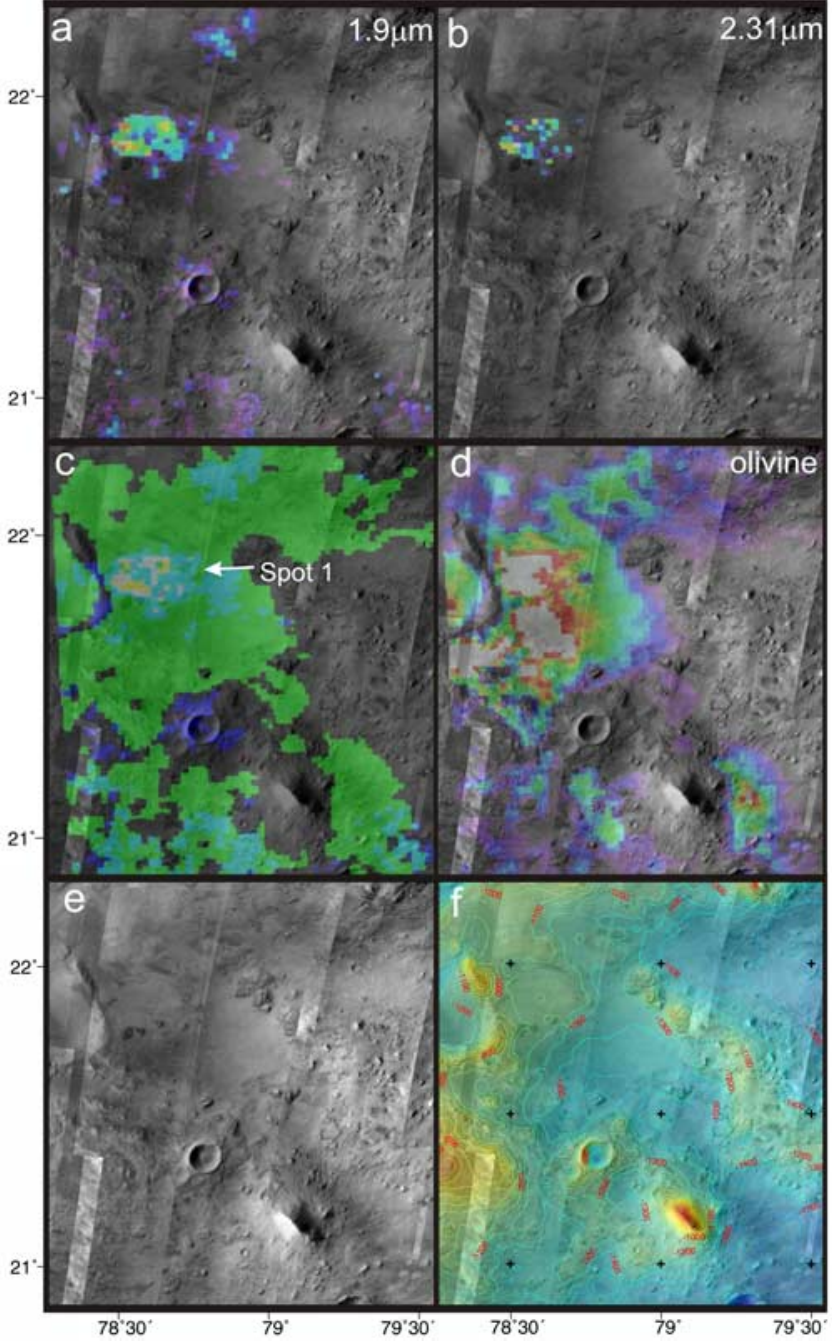

Figure 7. OMEGA data of orbit 2228 mapped over a mosaic of THEMIS visible images: (a) $\sim 1.9 \mu \mathrm{m}$ band, (b) $2.31 \mu \mathrm{m}$ band, (c) RGB map as in Figure 4, (d) olivine, (e) THEMIS visible images mosaic, and (f) MOLA topography over THEMIS mosaic. Band depths in Figures 7a, $7 \mathrm{~b}$, and $7 \mathrm{~d}$ as in Figure 6.

where the $\sim 1.9 \mu \mathrm{m}$ band is associated with the $\sim 2.3 \mu \mathrm{m}$ (Figure 5), at least over several pixels.

[21] At the western edge of the region, phyllosilicates with strong signatures are detected on an outcrop of Noachian basement surrounded by the Syrtis lava flows (Figure 9). One MOC image shows the contact of the Noachian highlands and lava flows (Figure 9c). The crustal outcrop displays local evidence of layering visible from their difference of tone. The surface appears relatively bright with typical albedo of 0.10 to 0.13 compared to 0.06 to 0.09 for Syrtis lava plains (as measured on the TES bolometric albedo map [Christensen et al., 2001]). Exhumation is visible from the observation of layering, but the surface exhibits a few small craters (diameter $<200 \mathrm{~m}$ ) suggesting that the action of erosion was limited.

[22] Two other close-ups show the important role of erosion in exposing crustal rocks at surface and possible relationships with internal processes (Figure 10). In the first example (Figures $10 \mathrm{a}$ to $10 \mathrm{~d}$ ), the material is apparently not layered, of intermediate TES albedo $(0.12$ to 0.15$)$ and locally eroded with residual buttes. The MOC close-up is characterized by etched terrain with relatively rough texture to the bottom of the image and smooth the middle of the image. Many faults cross the hydrated zone on the HRSC scale suggesting they played a role, but it is difficult to determine the precise geologic context in which phyllosilicates are detected.

[23] The second example (Figures 10e to $10 \mathrm{~g}$ ) displays a lobate tongue of Syrtis lava flows (SF) which covers the basement on which phyllosilicate signatures are detected. No hydration band is observed directly on the lava flows. A possible ancient volcanic cone $(\mathrm{V})$ is present $10 \mathrm{~km}$ to the northwest. This cone is visible from its rather circular shape of $6 \mathrm{~km}$ large with an open mouth to the south. The cone summit is located about $1 \mathrm{~km}$ above the surrounding plateau, right above the NE-SW fissure (Figure 10f). These characteristics are typical of scoria cones located on volcanic vents (see examples in Iceland [e.g., Thordarson and Larsen, 2006]) suggesting a volcanic activity in connections with fissures formation. At MOC scale (Figures 10f and $10 \mathrm{~g}$ ), the phyllosilicates are observed in association with many residual mesas and buttes suggesting terrains eroded over several tens of meters. This context suggests a possible interaction with nearby volcanism but the exact nature of the phyllosilicate-rich outcrop is nonetheless difficult to establish.

[24] OMEGA data also display strong exposures of LCP mixed with HCP in the Noachian basement [Mustard et al., 2005, 2007]. Hydrous minerals and pyroxenes are spatially decoupled. This shows that large parts of the crust are not hydrated. Nevertheless, signatures geographically small with shallow $\sim 1.9 \mu \mathrm{m}$ bands, usually devoid of $\sim 2.3 \mu \mathrm{m}$ band, are found throughout the Noachian units (Figure 5 and Figure 9). This suggests that the hydrous minerals are more widespread in the crust than seen from the previous examples. Due to the lack of high-resolution images, the correlation with geology of these patches is difficult.

[25] All signatures of hydrous minerals, whatever their size and precise composition, are detected on Noachian basement but none of them are detected on the Syrtis Major unit. The presence of hydrous minerals on the Noachian basement only suggests that their processes of formation was active during the Noachian period, but inactive after emplacement of the Syrtis Major lava flows in the Hesperian period [Greeley and Guest, 1987].

[26] The Noachian basement was classified as Noachian etched unit (Nple) on the geologic map because even at Viking resolution, this unit appeared to have been substantially eroded [Greeley and Guest, 1987]. This erosion is seen in Figures 9 and 10 as exhumed craters, layers and residual buttes. Erosion might be due to wind in the Amazonian period, suggesting that Syrtis Major lava plains are less eroded because they are more resistant, but it might also have begun earlier to the lava plains formation. As a consequence of the apparent erosion, in most cases, the formation of hydrous minerals was not limited to a surface layer. However, this erosion makes it difficult to know if the terrains on which hydrous minerals are detected correspond to rocks weathered at the surface or in the near-surface 


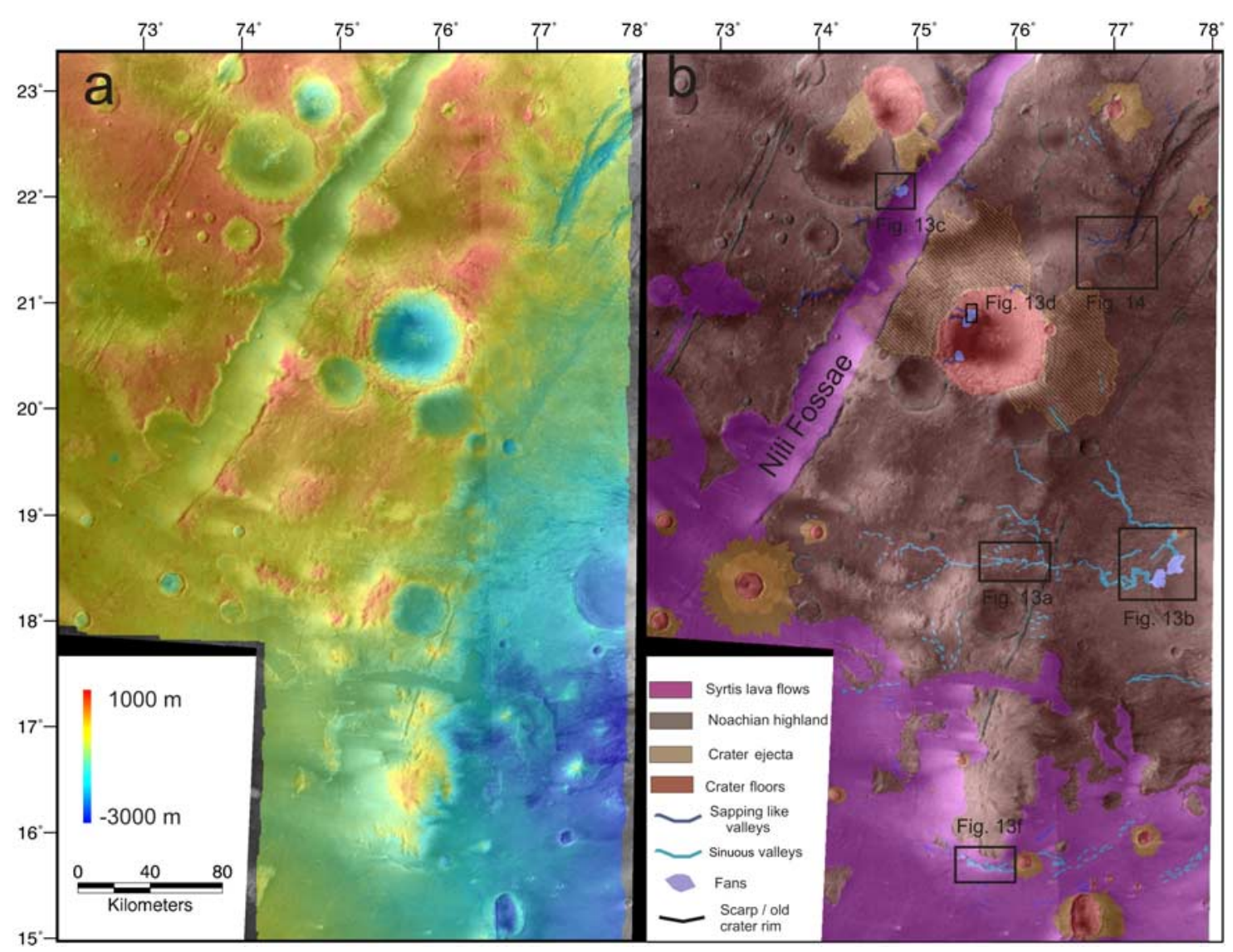

Figure 8. (a) Mosaic of HRSC images 1596, 1347, and 988 with HRSC calculated topography superposed. (b) Simplified geologic map of Nili Fossae region from HRSC images. Craters are colored only when ejecta is visible, even partially (dashed). Dashed blue lines indicate possible fluvial landforms.

linked to atmospheric processes, or altered in the deeper crust and exhumed, or both.

\subsection{Hydrous Minerals in Crater Ejecta}

[27] The $60 \mathrm{~km}$ large crater $\mathrm{C} 1$ (Figure 11) located in the middle of the context figure (Figure 5) is surrounded by ejecta stretching over tens of kilometers from the crater. High-resolution HRSC and MOC images show that hydrous minerals are located at the edge of these ejectas where erosion dissected their surface (Figures $11 \mathrm{~b}$ to 11f). The MOC images (Figures 11c and 11e) centered inside this ejecta confirm the typical elongated patterns usually visible in ejecta at high resolution. The erosion of the ejecta blanket is visible from the presence of buttes and dissected grooves (Figures 11c and 11e). Hydration bands observed southeast and east of the $\mathrm{C} 1$ crater are also interpreted to be related to the ejecta despite no MOC image can confirm this (Figure 11f). Here, the ejecta is strongly eroded and its outer edge is difficult to identify with lobate patterns being possible remnants of the ejecta front.

[28] Crater $\mathrm{C} 2$, which is northwest of $\mathrm{C} 1$, is shown in Figures 5 and 12. The ejecta of $\mathrm{C} 2$ shows signatures of hydration at the outer edge south and southeast of the $\mathrm{C} 2$ crater (Figures 12a, 12b, and 12c). These signatures are less clear than those of crater $\mathrm{C} 1$ with only a small fraction of the ejecta being hydrated. The presence of hydration in a few outcrops at the front of some ejecta (Figure 12a) suggests that the underlying bedrock contains hydrous materials too.

[29] For $\mathrm{C} 1$ and $\mathrm{C} 2$, the $\sim 1.9 \mu \mathrm{m}$ band is found with the $\sim 2.3 \mu \mathrm{m}$ band for a few area (see Figure $5 \mathrm{~b}$ for comparison), or often with the $\sim 2.3 \mu$ m plateau shape (Figures $2 \mathrm{e}$ and 2f), implying the presence of phyllosilicates in the ejecta, and locally smectites. Additionally, ejecta blankets of both craters $\mathrm{C} 1$ and $\mathrm{C} 2$ are partially draped over the floor of Nili Fossae, implying they formed after Nili Fossae floor emplaced, thus in the Hesperian period or later.

[30] In orbit 2228 data, a small crater of $5 \mathrm{~km}$ diameter (C3 in Figures 12d, 12e, and 12f) located in the center of the context image (Figure 7), displays a $\sim 1.9 \mu \mathrm{m}$ band spread on most of its ejecta and on the central peak. Here, there is no obvious $\sim 2.3 \mu \mathrm{m}$ feature; the single $\sim 1.9 \mu \mathrm{m}$ band signs the presence of hydrous minerals.

[31] The presence of hydrous minerals in ejecta of several craters can be due either to the excavation of these minerals from the crust or to the formation of these minerals by the impact (by hydrothermalism or impact metamorphism), for example due to subsurface volatiles. At this point, we cannot distinguish among these possibilities which are not mutually exclusive. We also note that not all crater ejecta have these signatures. This is not only an effect of partial exposure of other crater ejecta, since some of them display LCP signatures (see top of Figure 4 of Mustard et al. [2007]). Depending on the interpretation of minerals in 

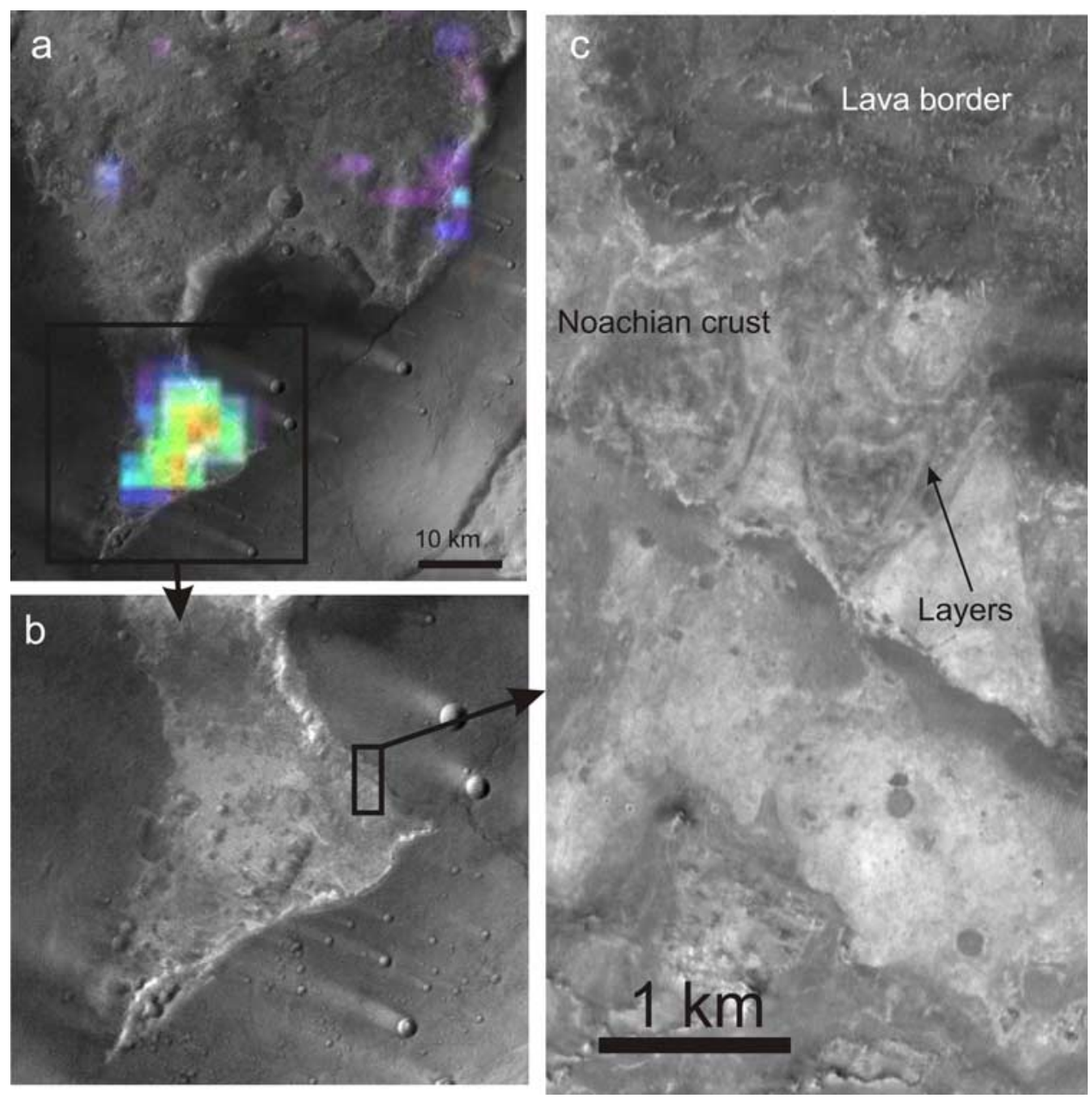

Figure 9. A striking example of phyllosilicates in the Noachian crust. (a) Close-up on the OMEGA map $(1.9 \mu \mathrm{m}$ band) of Figure 5a. Volcanic plains never display hydration bands. The spot of hydration to the NE is located at the base of the basement scarp. (b) HRSC image close-up on the outcrop with strong signatures of phyllosilicates. (c) Close-up on MOC image M07-01150. The Noachian basement has local layering and brighter rocks than the volcanic terrain.

ejecta (excavation, impact related process), the absence of hydration in other ejecta could either highlight the heterogeneity of hydrous minerals distribution within the upper crust, or show that groundwater vanished at some specific point in the past.

\subsection{Correlation With Fluvial and Sedimentary Landforms}

[32] Fluvial and sedimentary landforms are mapped in the HRSC mosaic (Figure 8). Three main types of landforms are observed in the studied region (Figure 13; see boxes in Figure $8 b$ ).

[33] First, ancient valleys cross the Noachian highlands (Figure 13a). These display sinuous shapes typical of meanders of fluvial origin, having a depth that reaches locally $300 \mathrm{~m}$ and extends up to $\sim 180 \mathrm{~km}$ in length. The valley floor exhibits a large channel with braided patterns typical of high-energy flows. A discharge of $500-900 \mathrm{~m}^{3} / \mathrm{s}$ was estimated for the EW oriented valley [Fassett and Head, 2005]. Two fans were deposited in a $40-\mathrm{km}$ crater by these EW-trending valleys (Figure 13b). Analysis of this valley-fan system suggests that the crater was filled by a lake during a period of sustained liquid water of probably thousands of years at minimum [Fassett and Head, 2005]. The origin of the water that eroded these valleys remains unknown (e.g., glacial melting, subsurface aquifers, rainfall or snowmelt following snow accumulation). The poorly branching geometry of these valleys is different from the usual dendritic valley systems observed on Earth for valleys formed by precipitation. Their width and the presence of large channels suggest better flash floods, subsurface discharge or glacial surges, but no evidence of theater-shaped heads suggests that the valleys formed by subsurface sapping and no glacial signatures such as moraines or grooves are observed close to the valley sources.

[34] Second, deep but poorly organized valleys emerge on the rim of the Nili Fossae trough system and some other landforms (Figure 13c). Their short length, theater-shaped head and constant width are typical of sapping canyons [Laity and Malin, 1985; Kraal et al., 1998], i.e., valleys formed by headward erosion due to subsurface flows. Several debris fans are associated with their termination in the Nili Fossae trough (Figure 13c). In contrast to the delta 

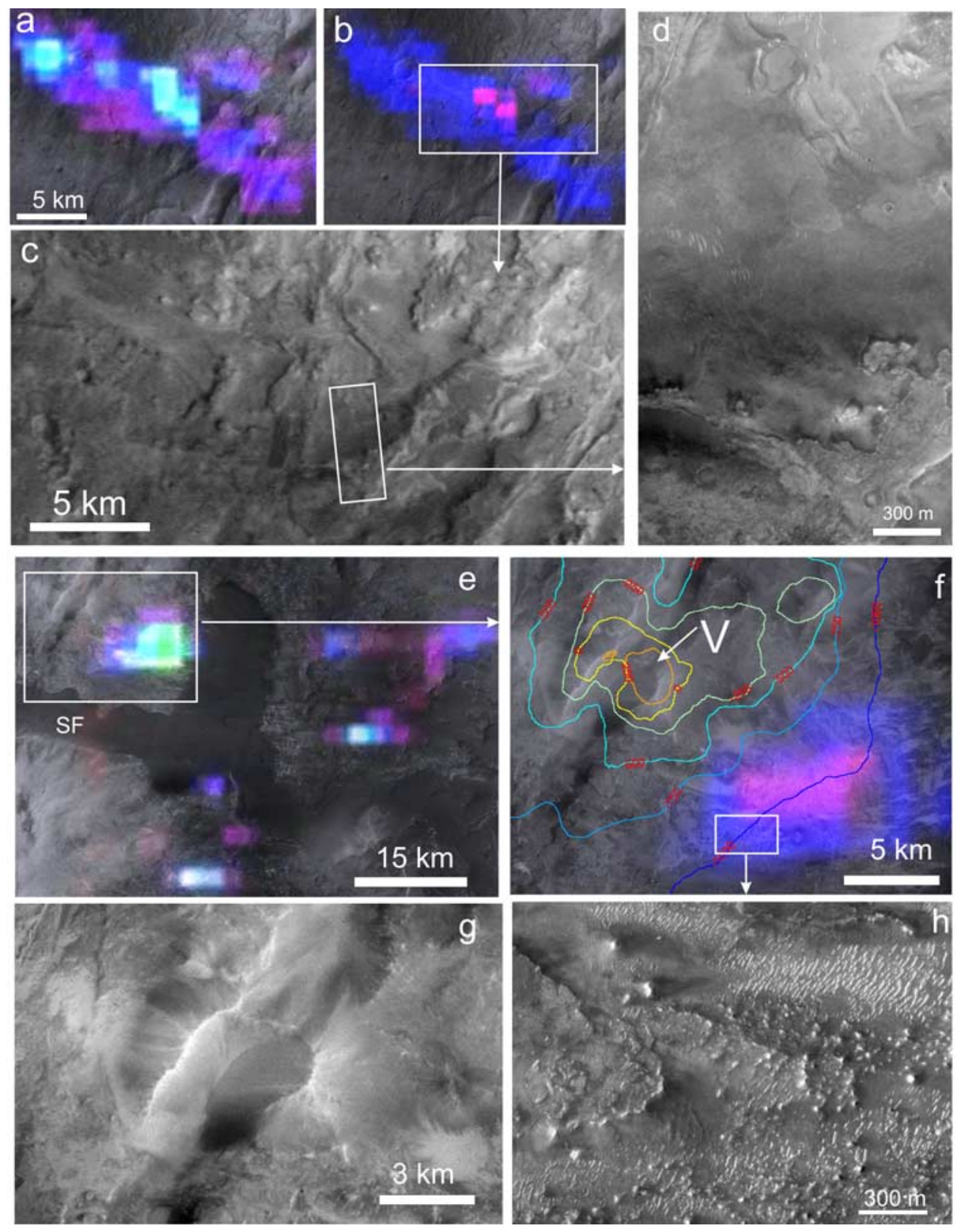

Figure 10. Two examples of phyllosilicates in the Noachian crust. (a) OMEGA close-up of Figure 5a with strong $1.9 \mu \mathrm{m}$ absorption band. (b) Same close-up with RB map as in Figure 5c. (c) HRSC close-up of the hydrated zone. (d) Part of MOC image R12-03583. (e) OMEGA close-up of Figure 5a with $1.9 \mu \mathrm{m}$ band. (f) Close-up of the area in Figure 10e with red-blue as in Figure 5c and HRSC DEM elevation contours. (g) HRSC close-up of the circular hill. (h) Close-up on MOC image M04-02904 of etched terrains with residual buttes suggesting exhumation of a few meters to tens of meters. SF, lobate flows from Syrtis volcanic system devoid of $1.9 \mu \mathrm{m}$ spectral feature; V, $1 \mathrm{~km}$ high circular hill interpreted as an old volcanic cone.

fans in the crater (sediment deposited subaqueously), these deposits are likely not deltas but alluvial fans (deposited subaerially). Additionally, another unusual fan is observed on high-resolution MOC images in the $\mathrm{C} 1$ crater (Figure 13d). It exhibits surface lineations typical of alluvial cones. Networks of polygonal cracks of a few tens of meters (Figure 13e) are observed on this surface suggesting either desiccation of a wet material or thermal contraction of an ice-rich material as seen at high latitudes [e.g., Mangold,
2005]. The depositional environment which formed this fan is unclear.

[35] Finally, a very distinct type of fluvial flow is observed on the lavas of Syrtis Major, at the south of the studied region. A deep and narrow valley is observed close to the lava-highlands contact. Upstream grooves are also observed as well as teardrop-shaped erosion typical of outflows channels. These observations suggest the occurrence of shallow but wide floods over the lavas of Syrtis 

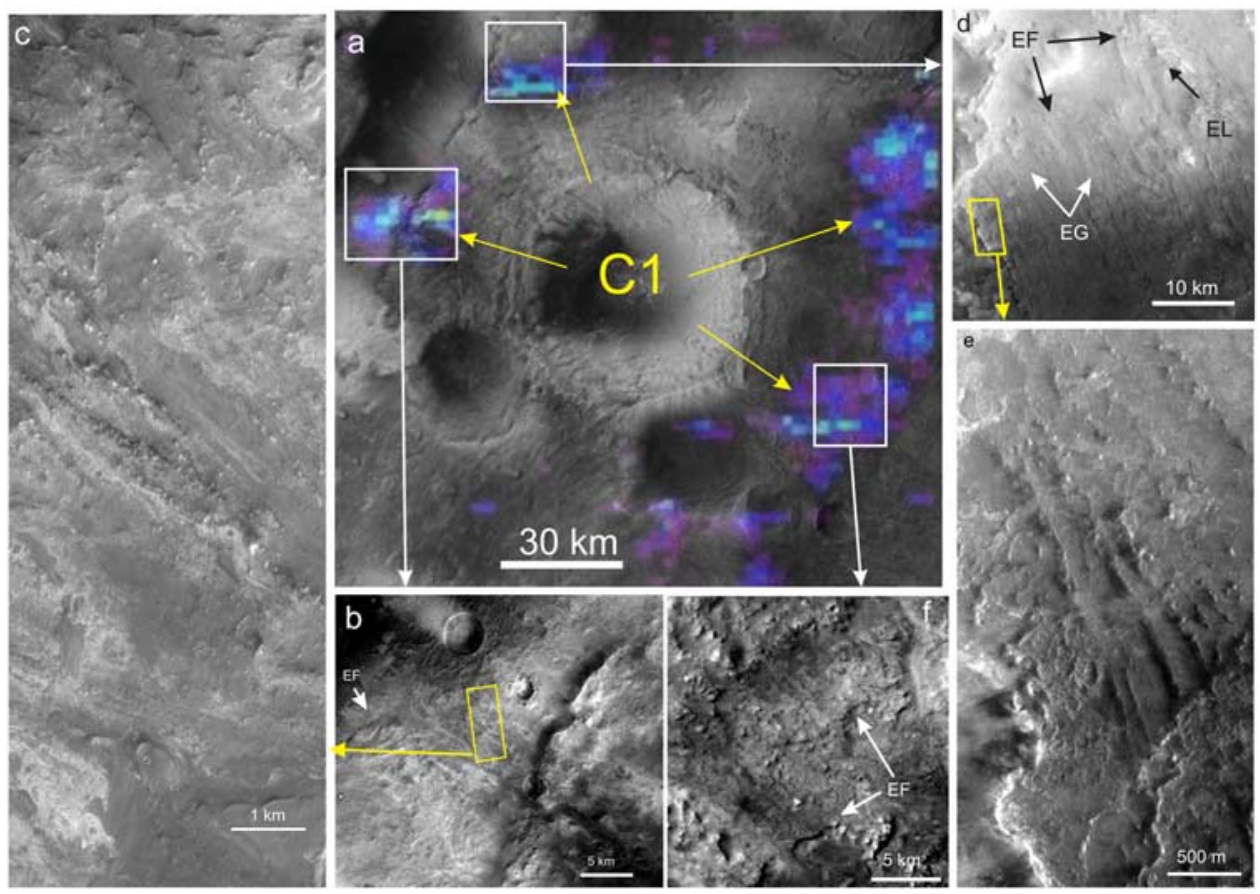

Figure 11. Close-ups of hydrated ejecta of crater C1. (a) OMEGA hydration band map of Figure 5 with yellow arrows showing ejecta directions. (b) HRSC close-up of the western ejecta. Lineations show grooves extending over Nili Fossae floor. (c) MOC image M11-02709 of the grooves in ejecta. The surface is partially eroded and exhibits large boulders. (d) HRSC close-up over northern edge of ejecta blanket. Hydration is present on the darker part of the ejecta only, likely because the brighter part is covered by dust. (e) MOC image S03-00168 showing ejecta grooves with eroded texture. (f) HRSC close-ups of southeastern ejecta blanket. The ejecta front is difficult to identify and exhibits a strongly eroded texture (no MOC available). EF, ejecta front; EL, ejecta lobes; EG, ejecta grooves.

similar to outflow channels in Xanthe Terra [Mangold et al., 2006a].

[36] The relative age of these landforms can be estimated from stratigraphic relationships. The outflow on Syrtis lavas is obviously post-Syrtis lava flows, thus of Hesperian age or later. The sapping valleys erode the canyons of Nili Fossae, and are therefore younger than the Fossae. Moreover, the terminal fan is visible on Nili Fossae floor (Figure 13c) therefore showing that the last period of activity of these sapping valleys occurred after Syrtis lava flows, as lavas of the Syrtis unit cover the floor of Nili Fossae. Two sapping valley heads also cut the border of the $\mathrm{C} 1$ crater showing a similar crosscutting relationship, because of the ejecta of $\mathrm{C} 1$ lying on the Nili Fossae floor. Both examples lead to a Hesperian age for, at least, the last episodes of the sapping valleys formation. Sinuous valleys and associated fans cross highlands and incise through many Noachian landforms such as circum-Isidis faults and craters. These valleys clearly postdate the formation of most Noachian units including the olivine-rich unit. At HRSC scale, several sinuous valleys might be superimposed on the eroded ejecta of crater $\mathrm{C} 1$. If this is the case, these valleys would also have formed after the $\mathrm{C} 1$ crater, but these observations need to be confirmed. These sinuous valleys and associated delta fans are thus either of the Noachian period, but postdate most geologic units including the olivine-rich unit, or of the Hesperian period. No obvious correlation between sinuous valleys and sapping valleys have been observed so far. The two types could have formed at same time or be disconnected with the sinuous valleys being more primitive.

[37] OMEGA spectral data show no obvious correlation between hydrous minerals and sinuous valleys, sapping valleys or the outflow channel. Local signatures can be found on highlands valleys (sinuous and sapping), but the signatures never follow the valleys geometry as expected for alluvial deposits. These signatures can correspond to local outcrops of bedrock. Terminal fans should be more likely to show the mineralogy of sediments but most fans (Figures 13b, 13c, and 13d) are devoid of hydration signatures, with the exception of one fan in the canyon crossed by orbit 988 (area A in Figure 6). Here, the top of layered deposits display a few $1.9 \mu \mathrm{m}$ bands at the location where the sapping valley emerges forming a terminal fan (yellow box in Figure 14a). This observation should be taken with caution because the signatures are small $(2 \%$ of band depth) and need to be confirmed. Notice that the surrounding basement rocks display stronger signatures.

\section{Correlation Between Hydration Signatures and the Olivine-Rich Unit}

[38] The correlation of OMEGA hydrous minerals detection with geologic features shows the presence of phyllosilicates associated with (1) layered material, (2) massive crustal outcrops, and (3) impact ejecta. On these three types, no other signatures such as pyroxene or olivine are detected. 

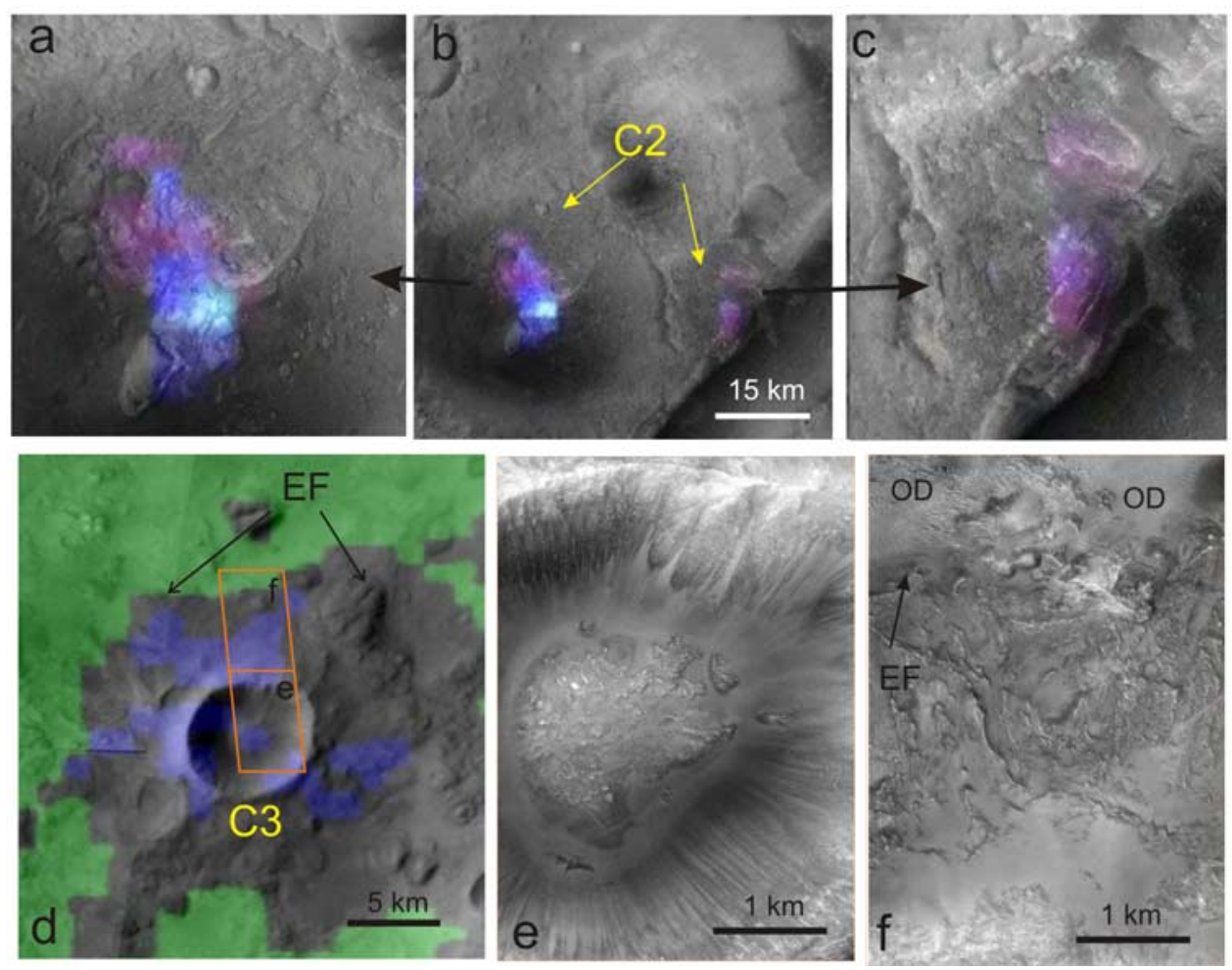

Figure 12. Close-ups over hydrated ejecta from craters $\mathrm{C} 2$ and $\mathrm{C} 3$. (a-c) Ejecta of crater $\mathrm{C} 2$ visible in Figure 5a with hydration signatures on both ejecta. Signatures are less developed than for C1. Incision in front of Figure 12a ejecta shows underlying material hydrated too. (d) Blue-green map as in Figure 7. (e and f) Close-up of MOC image E01-01891 of the crater C3 in the central peak and northern ejecta, respectively. Hydrous minerals are present on central peak and ejecta only. Olivine is detected out of the ejecta in the surrounding sand sheets. EF, ejecta front; OD, olivine-rich dunes.

In addition to these three types, hydration bands seen at $\sim 1.9 \mu \mathrm{m}$ and $\sim 2.3 \mu \mathrm{m}$ are also found close to olivine, or in the same spots, in the eastern part of the study area. We focus hereafter on three such areas where high-resolution MOC images are available: (1) area A of orbit 988 (Figure 6); (2) spot 1 where there is an extended association of hydration bands and olivine in orbit 2228 (Figure 7); (3) spots 2 and 3, the latter being less widespread than spot 1 (Figure 6).

\subsection{Geographic Association of Olivine With Hydrous Minerals}

[39] At the top of Figure 6, olivine is observed extensively on the plateau surrounding the NW-SE fractures. Olivine is found in a layered unit that exhibits a rough texture at the ten meter scale, typical of material strongly eroded by wind (Figure 15), in agreement with previous studies [Hamilton and Christensen, 2005; Mangold et al., 2006b; Martínez-Alonso et al., 2006]. This unit is discussed in detail in the companion paper [Mustard et al., 2007, Figure 6]. The hydrous minerals identified with the $\sim 1.9 \mu \mathrm{m}$ band display distinct geological relationships with the olivine units. In most cases the hydrous material is beneath the olivine unit, is homogeneous in texture, devoid of apparent layers, and locally crossed by lineaments with positive relief, i.e., dikes (Figure 15a, top right), with uncertain origin such as volcanic dikes or veins formed by fluid circulation. In other cases, some hydrated material is found in rocks overlying olivine-rich rocks (Figure 15a, bottom left). Here, the hydrated material is smoother and suggests a late burial by sedimentary deposits, possibly due to wind deposition. Thus, in this area, olivine-rich layers seem to be fresh but strongly eroded, with hydrous minerals present in the crust beneath the olivine units and locally over in the filled crater and the alluvial fans of Figure 14.

[40] Several pixels of hydrous material are also observed a few kilometers apart from olivine but without clear relationships to it, and outside crater $\mathrm{C} 3$. The olivine-rich area mapped in green in Figure 12 is restricted to locations around the ejecta of crater $\mathrm{C} 3$ and consists of dunes devoid of any hydration. As the ejecta are superimposed on the olivine-rich unit, the fact that no olivine is detected in the ejecta suggests that the olivine-bearing unit is thin and therefore the source of the altered material in the ejecta is located beneath this unit. Other hydration signatures are detected on the rim of a large impact crater (Figure 15b). These rims might have been altered at the surface, but probably previously than the olivine-rich unit formation which buries the crater floor. The impact rim might also correspond to excavation of deeper material as is the case for crater C3. In these two cases, most of the alteration seems to predate formation of the olivine-rich unit.

\subsection{Association of Olivine and Hydration Signatures}

[41] Spectra on spot 1 present both hydration and olivine bands over a surface of about $15 \times 20 \mathrm{~km}$. This associ- 

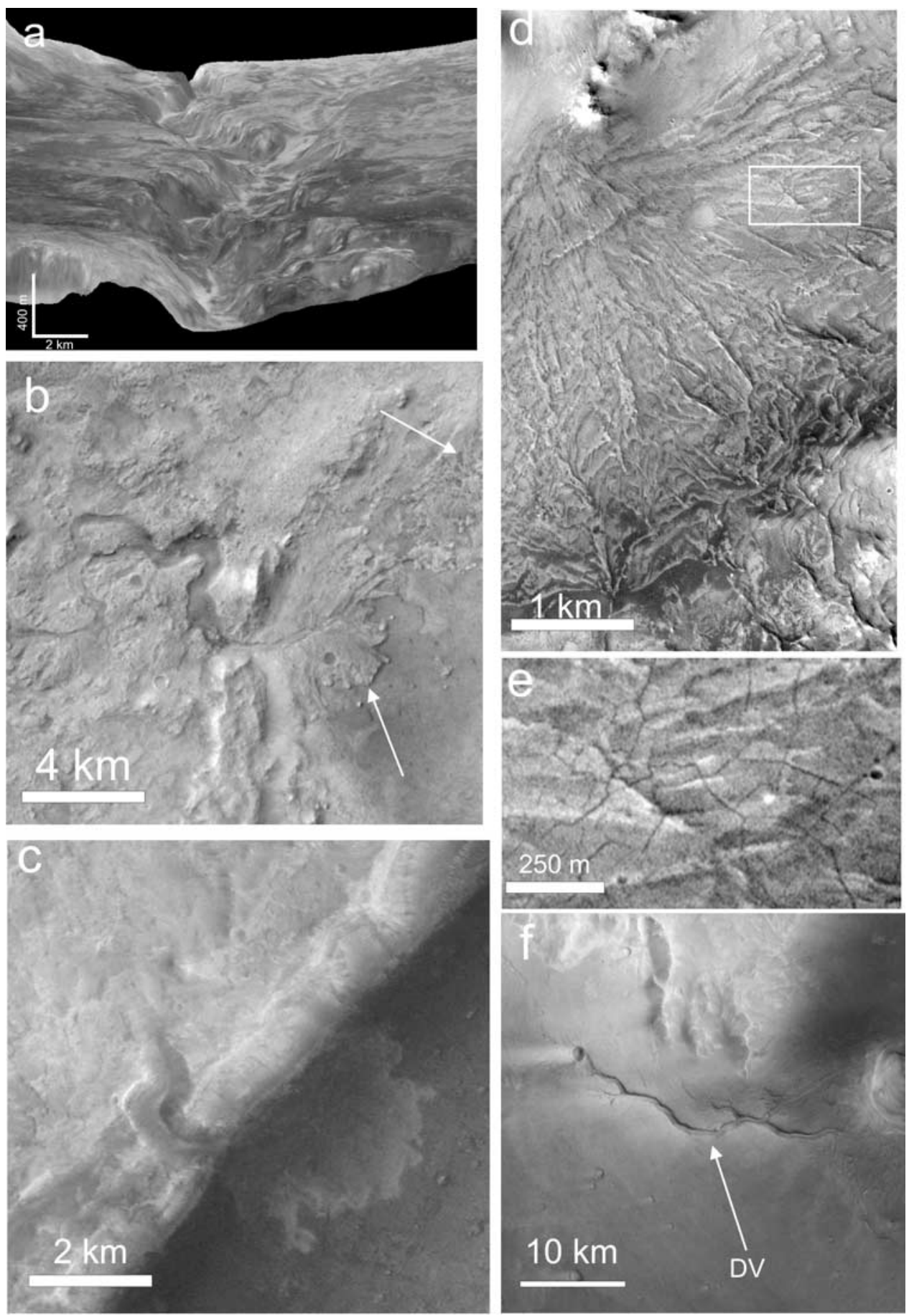

Figure 13. Close-up of different fluvial landforms in the Nili Fossae region (all HRSC except Figures 13d and 13e). (a) Meandering valleys in $300 \mathrm{~m}$ deep canyons probably carved by water (3-D sketch from HRSC DEM, view to the west). (b) Two fans (with arrows) at end of sinuous valleys inside a crater. (c) Short sapping-like valley with a terminal fan lying over Nili Fossae floor. (d) MOC image R11-02034 on a debris fan inside crater $\mathrm{C} 1$. (e) Close-up of the MOC image showing fan texture with polygonal cracks. (f) Deep valley (DV) on Syrtis Major volcanic plain.

ation may represent a spatial mixing or a microscopic mixing. Olivine is detected in three different types of surface (Figure 16). First, olivine occurs on surfaces with rough degraded textures (OR) in Figure 16 as on many olivine-rich outcrops (Figure 14) [Mustard et al., 2007, Figure 6]. The texture of these terrains shows evidence of significant erosion, probably by wind as seen from the local presence of parallel lineations of yardang-like features. Second, olivine is detected in sand dunes or sand sheets (OD), the latter being identified by a very smooth texture and local dunes, in widespread areas over the whole region. Sand dunes are likely the erosion products 

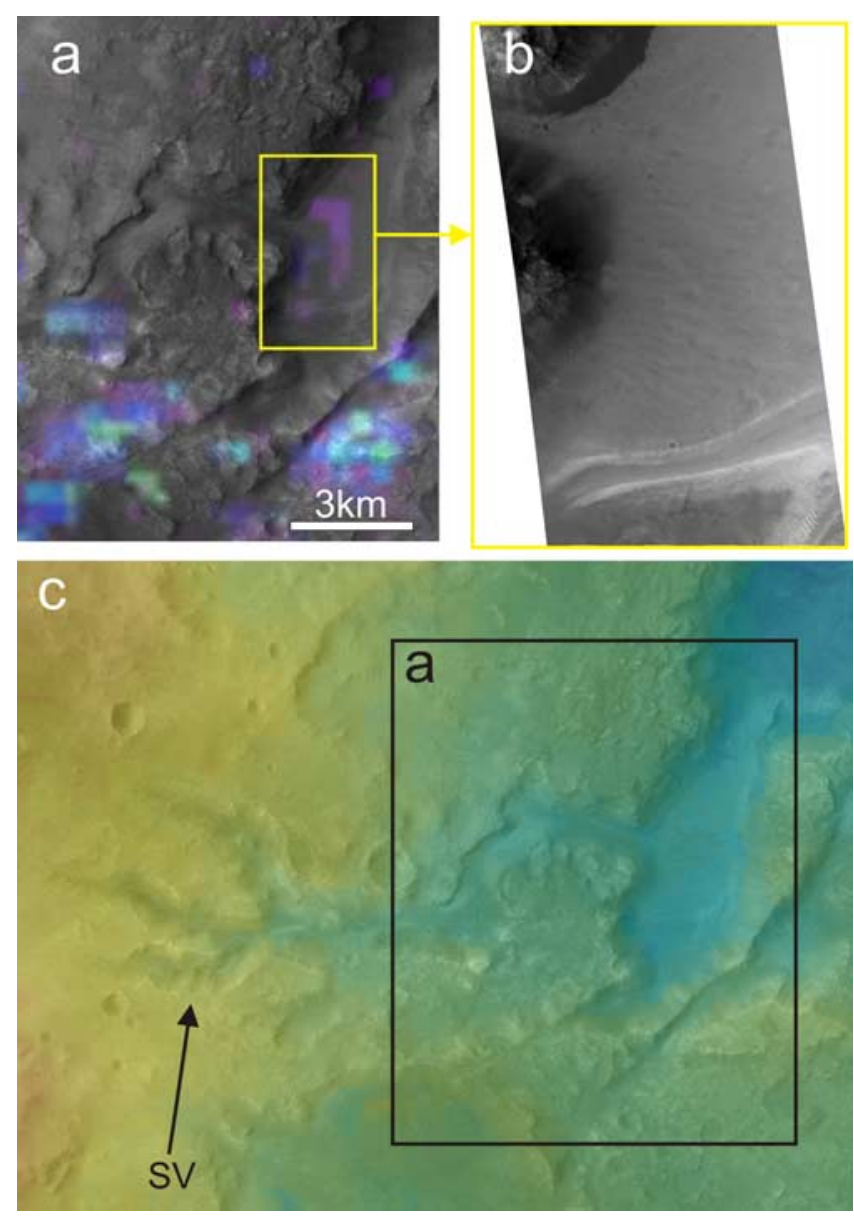

Figure 14. Hydrous minerals on a valley fan. (a) The $1.9 \mu \mathrm{m}$ band ( 0.02 to 0.05 band depth) in orbit 988 . Notice strong signatures on bedrock and weaker ones on depression floor. (b) Close-up on the depression floor (MOC E0500782) showing a flat surface with fine layering visible at front, likely consisting of a debris fan from the sapping-like valleys. (c) HRSC image with HRSC elevation superimposed in color. SV, sapping-like valleys with typical short size and broad width from the source area.

of the olivine-bearing rocks. Third, some olivine outcrops are smoother (OS) than the other outcrops of olivine but do not consist of dunes, with occurrence of sinuous landforms over a flat topography (Figures 16c and 16g). The sinuous landforms are interpreted as layering visible from albedo changes at MOC scale (arrow in Figure 16). When present on rough terrains or sand dunes, olivine is devoid of any hydration signatures. On the contrary, the smooth terrains with layering (OS) are associated with the signature at $\sim 1.9 \mu \mathrm{m}$ and at $\sim 2.3 \mu \mathrm{m}$, with a shift toward the $2.31 \mu \mathrm{m}$ band suggesting a higher $\mathrm{Mg}-\mathrm{OH}$ content. A similar correlation can be seen in the other MOC image which crosses spot 1 (Figure 17). Thus olivine is detected with hydration mainly on smooth terrains with local layering visible different from the other olivine outcrops (rough terrains and dunes). This observation implies that we do not have two spatially distinct geologic units for hydrous minerals and olivine, as observed in Figure 15, but a single unit with a specific texture over which both components are found.

\subsection{Local Areas of Olivine and Hydration Signatures}

[42] Additional associations of olivine with hydrous minerals are observed south of the previous region in spot 2 (about $30 \times 30 \mathrm{~km}$ ) and spot 3 (about $2 \times 2 \mathrm{~km}$ ) of orbits 2228 and 988 (Figure 4 and Figure 18a). On spot 2, many pixels on the RGB composition maps display turquoise ( $\sim 1.9 \mu \mathrm{m}$ band and olivine) and even an orange color ( $\sim 1.9 \mu \mathrm{m}, \sim 2.3 \mu \mathrm{m}$ band and olivine). These signatures occur mainly on the same group of pixels in the center of the olivine-rich area and not on the periphery of two distinct signatures (Figure 4). These observations favor microscopic mixing for spot 2 rather than spatial mixing, but we are limited by the resolution of available images. Only spot 3 can be seen at MOC resolution. The interesting spectra are found on the flat intermediary plateau of a strongly eroded hill (Figure 18). This surface does not show two distinct rock units, but the size of this spot limits interpretations. Notice the MOC image shows interesting patterns (elliptical features at the ten meter scale with associated sinuous shapes pointed out by the arrow in Figure 18) that would be interesting to target for higher resolution instruments.

\section{Discussion}

[43] The presence of phyllosilicates, and especially smectites, is a strong indicator of the occurrence of low-temperature alteration (lower than $500^{\circ} \mathrm{C}$ [e.g., Güven, 1988]). A broad set of processes can create these minerals, from surface weathering to subsurface alteration at relatively higher temperatures through hydrothermal processes.

\subsection{Origin of Phyllosilicates in Crater Ejecta}

[44] Phyllosilicates contained in crater ejecta provide important constraints on alteration, but the mode of their origin requires further exploration. Phyllosilicates may be present in ejecta either (1) by in situ alteration by the impact process itself (assuming this high-temperature mechanism able to form phyllosilicates), or (2) by subsequent hydrothermalism (at lower temperature able to form phyllosilicates), or (3) by the presence of these minerals in the impact projectile (assuming in enough proportion to explain the detection). Alternatively, they could come from (4) the excavation of buried material altered before impact at the surface or subsurface. We see next that the excavation hypothesis can explain the distribution of hydrated ejecta observed better than other hypotheses.

[45] The spectral data shown in Figure 2 indicate a frequent $\sim 2.3 \mu \mathrm{m}$ plateau shape in the ejecta, which suggests a variation of composition possibly due to the formation mechanism, for example between high-temperature alteration associated with impact and low-temperature weathering processes which would form or transform various minerals. Alternatively, this difference might also be explained by strong mixing that occurs during the impact and would have mixed different types of phyllosilicates present, explaining the lack of an obvious $\sim 2.3 \mu \mathrm{m}$ band. For example, it is likely that a mixing of $\mathrm{Fe}, \mathrm{Mg}, \mathrm{Al}-$ smectites with metal-OH bands of slightly different wavelengths would enlarge the band but decrease its depth. Thus 


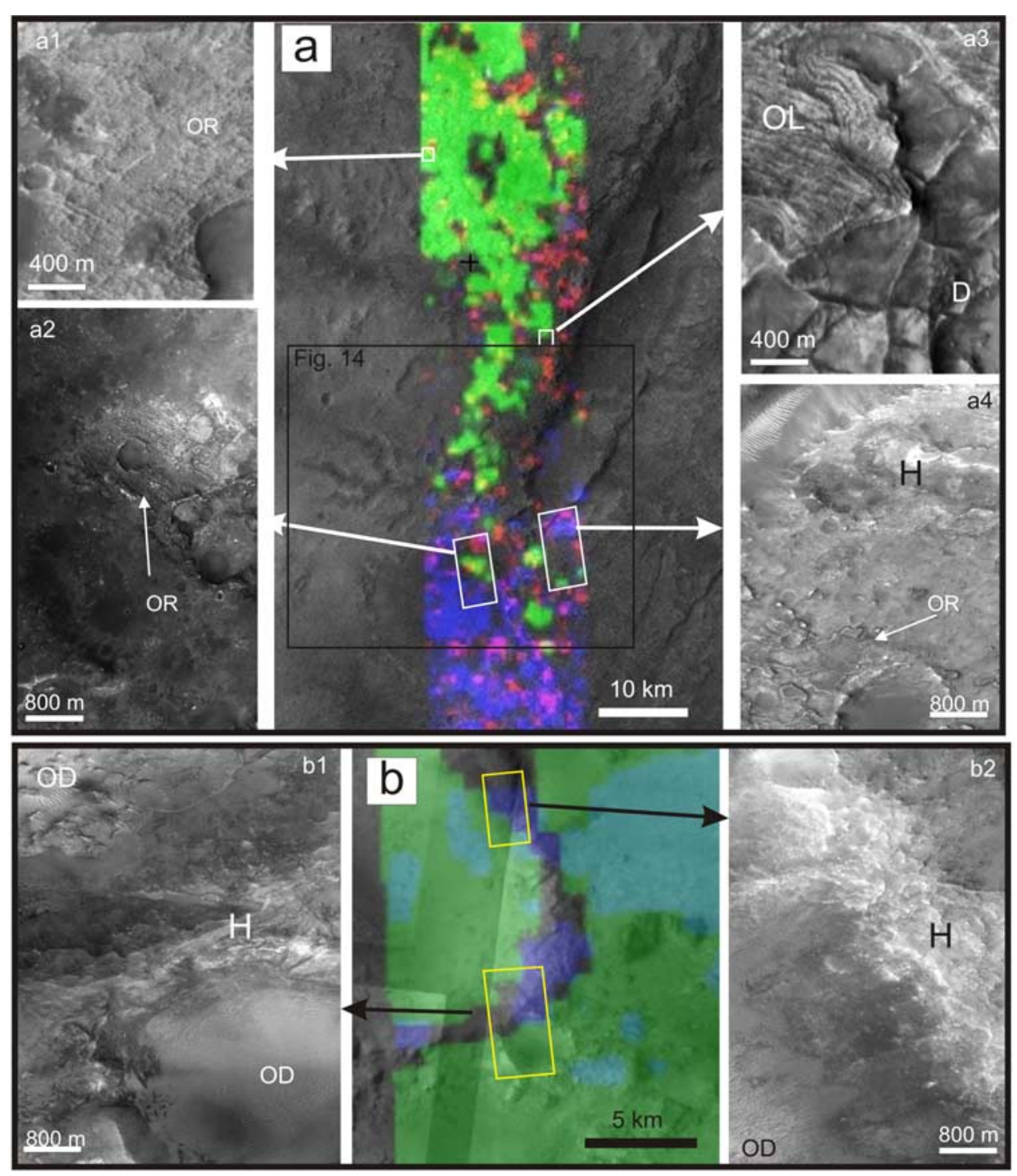

Figure 15. Hydrous material close to olivine outcrops. (a) Enlargement of Figure 6d. Red and blue colors are often associated, indicating phyllosilicates. (a1) Olivine-rich outcrop with rough terrain without hydration (MOC E04-01841). (a2) Piece of rough olivine-rich terrain surrounded by hydrous material apparently mantling the olivine (MOC R01-00614). (a3) Olivine present on a layered unit. A unit with dikes is present beneath the olivine-rich layers (MOC E05-00872). (a4) Pieces of rough olivine outcrops over a crust with local phyllosilicate outcrops (MOC E05-00872). (b) Blue-green map as in Figure 7. (b1 and b2) MOC R12-02694 with olivine on dunes and hydrous material seen on the impact rim. OR, olivine over rough terrain; OD, olivine dunes; OL, olivine in layers; H, hydrous material; D, dike unit.

the variation in composition cannot help us to discriminate the formation process.

[46] After two years of operation, OMEGA detects phyllosilicates on crater ejecta mainly in Noachian terrains, with only one potential exception [Costard et al., 2006]. This likely implies that volatile interactions became unimportant for impacts after the Noachian period, and Hesperian surfaces should not display hydrated ejecta. However, it is important to note that all craters formed in Noachian terrains are not of Noachian age. Indeed, ejecta from craters $\mathrm{C} 1$ and C2 both overlay the Nili Fossae floor, and thus their projectiles had to have impacted the planet in the Hesperian period or later. So, if phyllosilicates formed by the impact process into a volatile-rich subsurface (hypothesis 1), hydrated ejecta should be widespread in post-Noachian terrains too. A variation in the subsurface porosity between Noachian crust and later volcanic material could be invoked to explain this variation, but it would not explain the complete absence of hydration, because volatiles can be stored in lava fractures or ash deposits. This reason also disfavors any hydrous material present in the impact projectile (hypothesis 3 ), because meteorites have no reason to be phyllosilicate-rich only in the Noachian period. This key observation implies either a post-impact formation by hydrothermalism or excavation.

[47] Phyllosilicates are visible in the ejecta of craters, not on the floor of these craters, with exception of the crater $\mathrm{C} 3$ where it is found on the central peak (Figures 12d and 12e). 

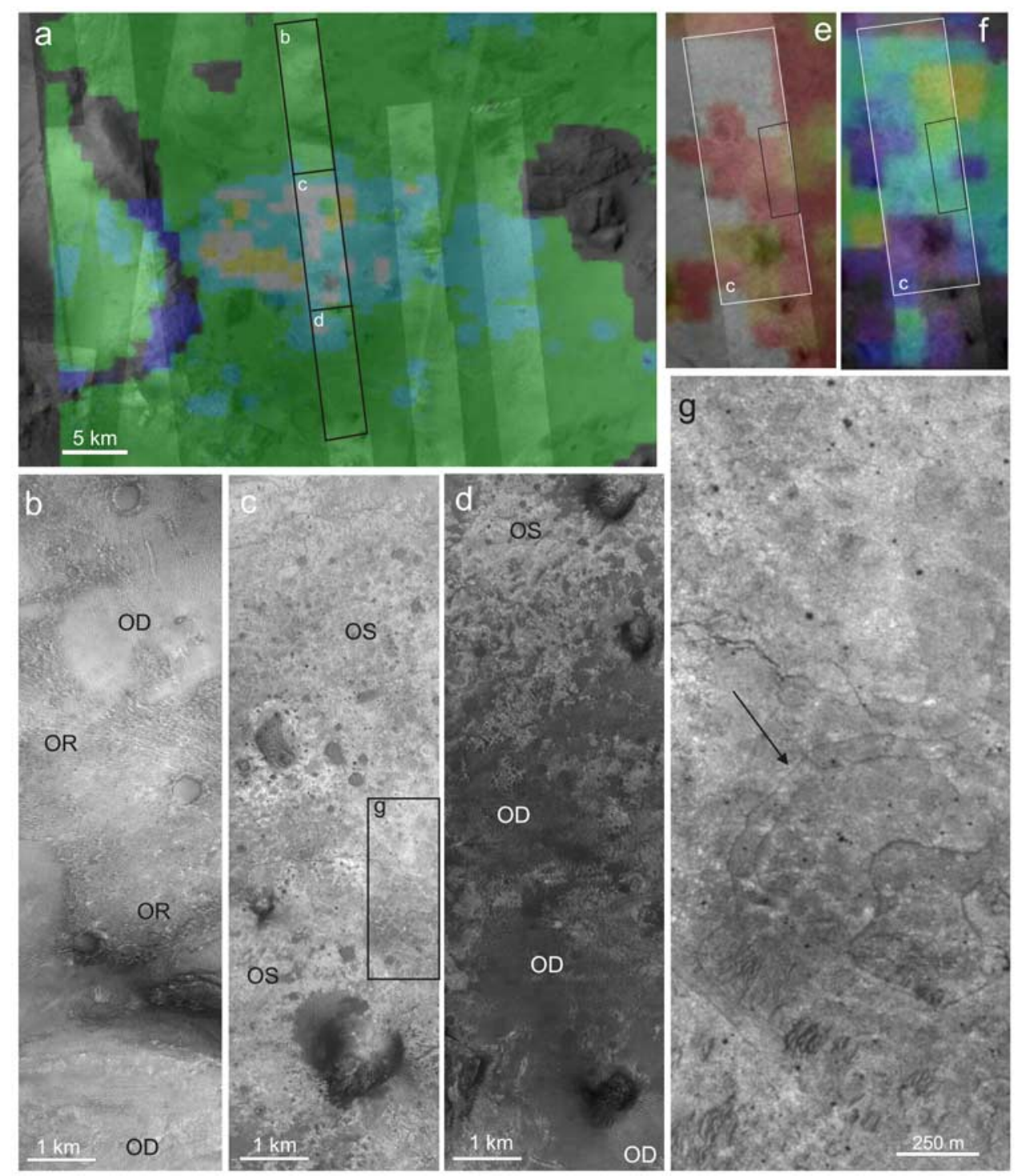

Figure 16. Olivine together with phyllosilicate-like signatures on same spectra of orbit 2228 . (a) OMEGA RGB map as in Figure 7 around spot 1. Figures 16b, 16c, and 16d are close-ups of the MOC image M22-02199. Outcrops in Figure 16b are hydration free. These areas show only olivine in rough terrains (OR) or eolian dunes (OD). The Figure 16c close-up is centered on spot 1 dominated by a flat plain with smooth texture (OS). Outcrops in Figure 16d show the same smooth terrain at the top left, whereas the rest of the image is free of hydration with mainly olivine dunes. Figures 16e and $16 \mathrm{f}$ are close-ups of Figure 7 of olivine and $1.9 \mu \mathrm{m}$ band depth, respectively, on the central part of spot 1. Figure $16 \mathrm{~g}$ is a view of the smooth texture of the olivine area with strong hydration signatures. The arrow points to lineations interpreted as fine layering visible from a slight albedo difference. OD, olivine-rich dunes; OR, rough olivine outcrops; OS, olivine and hydration over a smooth texture.

Hydrothermal alteration after impact processes would be expected to be as developed (if not more developed) on the impact floor as on the ejecta [e.g., Abramov and Kring, 2003]. This observation is inconsistent with the post-impact hydrothermalism (hypothesis 2), but the interpretation is limited by the possible presence of mantling on craters floor which could hide signatures. The ejecta of the three craters $\mathrm{C} 1$ to $\mathrm{C} 3$ are hydrated but devoid of any pyroxene signatures too. On the contrary, HCP- or LCP-rich ejecta exist either on the highlands [Mustard et al., 2007, Figure 4], or in the Syrtis Major plains [Baratoux et al., 2006], and are devoid of hydration despite having the same morphology (lobate ejecta blanket) and size range $(10-80 \mathrm{~km})$. Thus, if all the ejecta were the result of the same impact or postimpact hydrothermal interactions (hypotheses 1 and 2), one would need to explain why the hydrated ones have completely lost any pyroxene signatures. In contrast, an excavation process (hypothesis 4) is consistent with such geographic variation if the basement is heterogeneous in composition, as observed in section 4.1.

[48] Attributing hydrated ejecta to excavation of phyllosilicates or other hydrous minerals has many implications. 

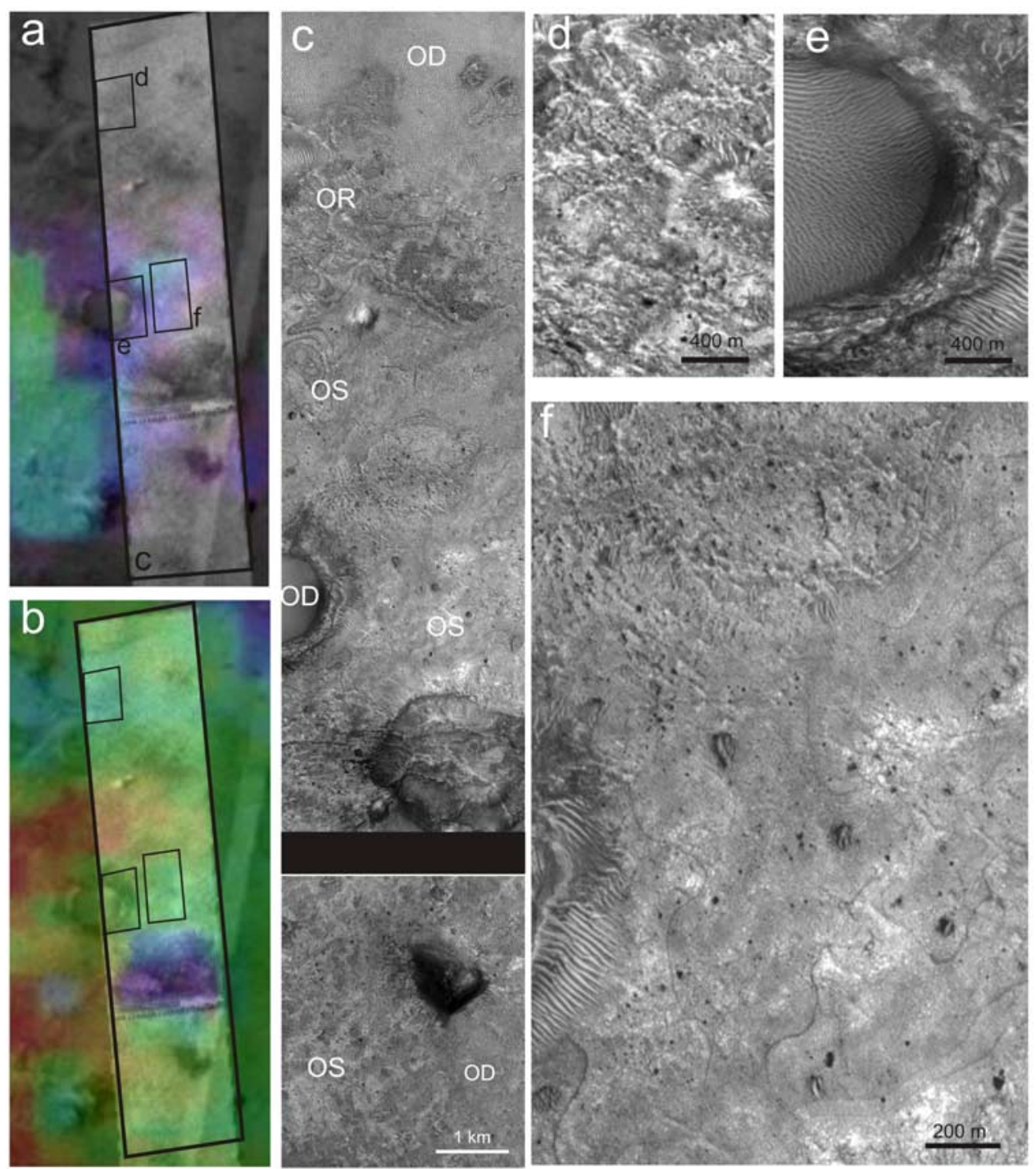

Figure 17. OMEGA spectra with (a) $1.9 \mu \mathrm{m}$ band depth and (b) olivine signature as in Figure 7. Squares on the OMEGA maps correspond to close-ups of the MOC image. (c) MOC image M22-00355 with different textures. Hydration with olivine mostly distributed in smooth plains (OS). (d) Close-up over olivine-rich area without hydration showing rough material. (e) Olivine-rich dunes at the bottom of a $1 \mathrm{~km}$ large crater. (f) Close-up on the smooth surface with lineations. On top, hydration seems also present on a surface with texture slightly rougher than on the smooth plains (OS). Notice the hill south of the MOC devoid of hydration and almost olivine free. This hill appears as a relic of the material buried beneath the olivine unit. OD, OS, and OR as in Figure 16.

First, these minerals must have survived the heat of the impact. We note a difference in the $\sim 2.3 \mu \mathrm{m}$ band at these ejecta locations in comparison with other locations (Figure 2). This difference might be due to a difference in the material excavated or to transformation during excavation. Second, phyllosilicates are detected on the outer edge of ejecta of craters $\mathrm{C} 1$ and $\mathrm{C} 2$, not close to the impact rim. The most distal ejecta corresponds to materials which are in the upper part of the pre-impact stratigraphy because these layers experienced the highest velocity during impact (Figure 19a). Deeper materials remain close to the crater rim because of lower velocities [Melosh, 1989]. Thus the presence of phyllosilicates in the outer part of the ejecta only suggests that these minerals come from the uppermost part of the crust, i.e., a few hundreds of meters deep. An alternative possibility would be that proximal ejecta are not as eroded and do not present outcrops large enough to show any signatures. Finally, the nature of the excavated bedrock is uncertain. It is difficult to distinguish between two possibilities (Figures 19b and 19c): ejecta might come from (1) hydrous minerals present in buried sedimentary or volcanic units, formed originally at the surface, or (2) rocks altered at depth by fluid circulation. In summary, we favor the formation of hydrated ejecta by excavation (hypothesis 4), but we cannot fix the origin of the material and we do not exclude the possibility of impact modification of this material as that due to a volatile-rich subsurface. 

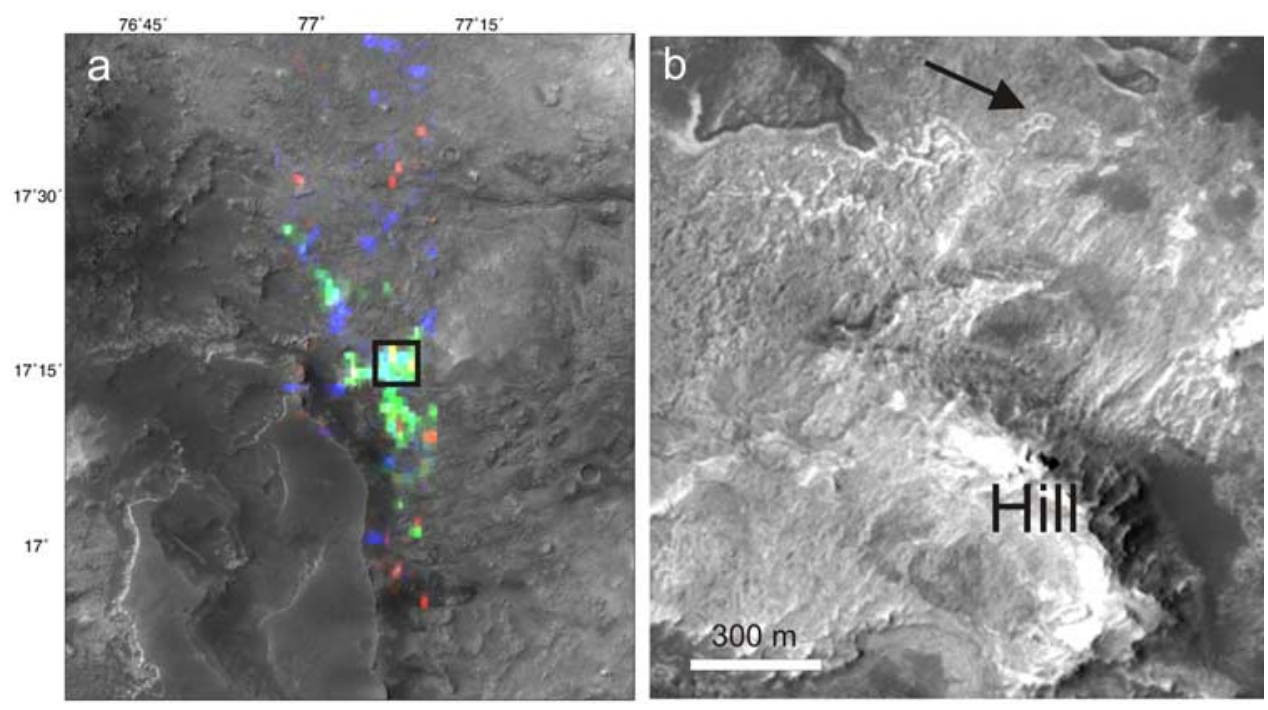

Figure 18. Spot 3 of olivine and hydration bands on the same spectra. (a) Close-up of OMEGA map as in Figure 6. (b) MOC image R02-00927 centered on the spectra with the three signatures (olivine, $\sim 1.9 \mu \mathrm{m}$ and $\sim 2.3 \mu \mathrm{m}$ band in RGB as in Figure 6). The arrow points out an elliptical feature with sinuous features associated.

\subsection{Relationships With Fluvial Landforms}

[49] The geographic distribution of clay minerals is mainly disconnected from fluvial and depositional landforms with the potential exception of one terminal fan (Figure 14). This conclusion is limited by the size of terminal fans: some of them might not have rock exposure large enough to be detected in OMEGA spectra. The fact that no pyroxene is detected on some of them neither confirms this limitation. Moreover, the presence of clays in the eroded bedrock of some valleys should lead to the erosion and accumulation of clays in terminal fans too. Assuming that the detection on a fan is valid (Figure 14),

a.

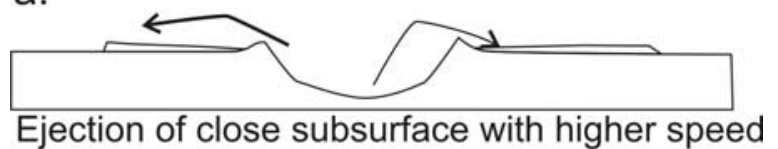

b.

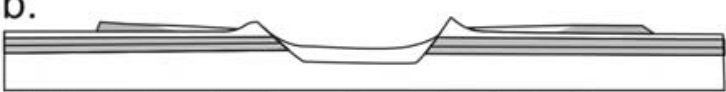

Hydrated rocks in sediments at depth

C.

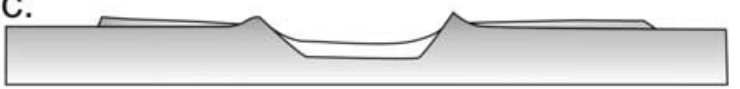

Hydrated rocks in crustal (altered megaregolith or lavas)

Figure 19. Figures illustrating the distribution of hydrous minerals in ejecta. (a) Outer ejecta formed in upper subsurface with higher velocities, inner ejecta with lower velocity and deeper material. (b and c) Two possibilities to explain the alteration of the subsurface, as buried layers (Figure 19b) or hydrothermal circulation more important close to the surface (Figure 19c). this observation may account for the deposition of hydrous minerals from the aqueous flows, thus suggesting either (1) the occurrence of water activity was long enough to form hydrous minerals, or (2) hydrous minerals comes from the erosion, transport and deposition of material originally contained in the crust. The second hypothesis is favored because the fan is surrounded by strong signatures of hydrous minerals suggesting that alteration during fluvial processes is not necessary to explain the observation (Figure 14).

[50] Surface weathering by running water can be associated with phyllosilicate formation and deposition if the action of water is long enough [e.g., Velde et al., 1995]. Fluvial landforms and their depositional products formed late in this region: all of them formed after the emplacement of the Noachian units that are rich in LCP, olivine or phyllosilicates, with some of them (sapping valleys especially) being active during the Hesperian period. It is thus not surprising that the observed fluvial landforms are poorly correlated with hydrated regions: they cannot account for the epoch in which the phyllosilicates formed. Moreover, the overall erosion of the terrain in Nili Fossae region does not allow us to see the most primitive landforms. For example, well ramified valley networks usually identified in Noachian regions are not observed in the Nili Fossae area; if they once existed they might have been eroded or buried.

[51] This result also has therefore some implications for the climate at the end of Noachian and during the Hesperian, the epochs during which the observed fluvial landforms formed. Despite the fact that we have a limitation in the observations (i.e., fan size), we could have expected that a long-term fluvial activity would have generated more widespread alteration deposits and correlation with fluvial landforms. In order not to be associated with such an abundant alteration material, the fluvial episodes were either limited in time ( $\mathrm{t}<10,000$ years), or in intensity (arid 
climate), or developed at temperatures close to the freezing point, impeding strong alteration. Indeed, in cold climates $\left(<10^{\circ} \mathrm{C}\right.$ of average surface temperature), smectites formed over $100 \mathrm{~s}$ to $1000 \mathrm{~s}$ years [Gillot et al., 1999; Righi et al., 1999; Meunier, 2003]. Similar timescales seem required to weather Martian analogues rocks [Browning et al., 2003], but longer periods might be involved in an arid climate with only ephemeral activity. This general observation is interesting to compare to the presence of other terminal fan deposits on Mars, formed at the Late Noachian-Early Hesperian boundary or later, interpreted to result of lacustrine activity [Moore and Howard, 2005; Irwin et al., 2005; Fassett and Head, 2005; Mangold and Ansan, 2006]. Our study suggests that these landforms formed over specific conditions (a limited period of time, arid climate or low temperatures), since in general they lack any clear association with extensive phyllosilicates.

\subsection{Origin of Hydration in Olivine-Bearing Rocks}

[52] The association of olivine and hydrous signatures may represent a spatial mixing (1) if the mixing consists of an olivine-rich unit partially covered by a thin dust mantle enriched in phyllosilicates, or (2), if the mixing consists of two geologic units associated at OMEGA subpixel scale, or, alternatively, (3) it can reveal a microscopic mixing of phyllosilicates and olivine-rich material due to a partial alteration of mafic rocks. The surface observed at MOC scale is different from a spatial mixing of dust and rocks because the extraction of thermal inertia from THEMIS night data shows values of 300 to $500 \mathrm{~J} \mathrm{~m}^{-2} \mathrm{~K}^{-1} \mathrm{~s}^{-1 / 2}$ [Hamilton and Christensen, 2005] typical of terrains with mixtures of bedrock and gravel, not dusty terrains. In the second case, a spatial mixing between two type of rocks could reveal the presence of hydrous material present beneath the thin olivine-rich unit and locally outcropping, as suggested by the presence of hydrous minerals in part of the surrounding basement (Figure 7). However, when the underlying basement is visible from residual hills inside spot 1 (Figure 17), these hills do not present hydrous minerals. On the contrary, observations of spot 1 (Figures 16 and 17) show that the hydrated olivine outcrops have unique surface characteristics favoring a microscopic mixing. Indeed, if hydrous and olivine signatures were two distinct geological units, we would likely observe two distinct textures at MOC scale, because olivine and clay minerals have different behaviors to erosion. The fact that the olivine band depth is very strong in the hydrated part is also an argument against a spatial mixing because a spatial mixing of different species should decrease their respective signature inside the mixing zone. Thus, in the following, we focus our discussion on the implication of a microscopic mixing, with hydrous signatures being an alteration product of the olivine-rich unit.

[53] Olivine is usually the first mineral to be altered in mafic rocks [e.g., Gislason and Arnorsson, 1993]. The preservation of olivine in the presence of hydrous material, with olivine signatures as strong as in unaltered sand dunes, suggests that olivine has been poorly altered, which raises questions about the nature of the observed alteration product. The usual sequence of alteration of minerals during experimental dissolution shows pyroxene dissolved after olivine. However, the alteration of minerals in basaltic rocks also depends on two other parameters: grain size and the presence of glass.

[54] First, amorphous glass dissolves more rapidly in water than any of the mafic minerals [Gislason and Arnorsson, 1993; Chesworth et al., 2004]. In that case, an alteration of a mixing of olivine grains with glasses could leave the olivine unaltered whereas glasses could have been partially transformed. Second, large crystals are usually preserved longer during alteration relative to small grains mixed in the mesostasis $(<10 \mu \mathrm{m})$ [e.g., Gislason and Arnorsson, 1993]. This observation of grain size as a major parameter in the sequence of alteration is very common on Earth. Laboratory experiments have shown that grains $1 \mathrm{~mm}$ large alter into clays about 1000 times more slowly than grains of the same composition $1 \mu \mathrm{m}$ large [Browning et al., 2003]. Sand dunes coming from the olivine-bearing units are ubiquitous in the region, thus suggesting that olivine grains of sizes of about $100 \mu \mathrm{m}$ or more dominate the mineralogical assemblage. Preliminary modeling of OMEGA spectral data of olivine-rich rocks on Mars show that a widespread presence of olivine millimeter size grains can explain the strong signatures observed [Poulet et al., 2006]. Thus the large grain size of the olivine compared to a fine-grained matrix of different composition might have partially preserved it from alteration.

[55] A last observation is that the metal-OH band, for the olivine-bearing unit that exhibits a hydration signature, is found at $2.31 \mu \mathrm{m}$, while it is more frequently observed at $2.29 \mu \mathrm{m}$ in other locations. This might show an enrichment in $\mathrm{Mg}-\mathrm{OH}$ relative to $\mathrm{Fe}-\mathrm{OH}$ whereas the olivine detected seems to be much more Fe-bearing than Mg-bearing [see Mustard et al., 2007]. This small difference can be explained by one of the two following possibilities: (1) Mg-ions are leached first in the alteration fluids leaving the olivine more Fe-bearing [Chesworth et al., 2004], then implying an alteration of the olivine grains, or (2) the alteration transforms a mesostasis of pyroxene-rich composition, not detected by OMEGA, but likely to exist because olivine would not account for $100 \%$ of the minerals present in the rock. In the latter case, the alteration could be limited enough to alter the mesostasis, but not the olivine grains.

[56] Given these observations, we propose two types of mineralogical assemblages leading to preserved olivine grains in a partially altered rock: (1) olivine grains are partially altered due to alteration rinds and/or veinlets, or (2) alteration has degraded the rock but large olivine grains have been preserved (Figure 20). A combination of the two is also possible.

[57] The first case (Figure 20a) is typical in terrestrial alteration at depth in association with fluid circulation and fractures. The presence of alteration involving clay minerals has been noted in fractures of SNC meteorites [Treiman et al., 1993; Watson et al., 1994; Treiman and Lindstrom, 1997; Borg and Drake, 2005]. For example, olivine grains are partially degraded into clay minerals in veinlets of the magmatic material inside Nakhlite meteorites [Gillet et al., 2002]. This might be consistent with a situation where the olivine is progressively depleted in $\mathrm{Mg}$ as it is partitioned into smectite-like minerals. A problem with this case is that the volume of phyllosilicates produced in alteration veinlets is usually a small proportion of the olivine-bearing rock, so 


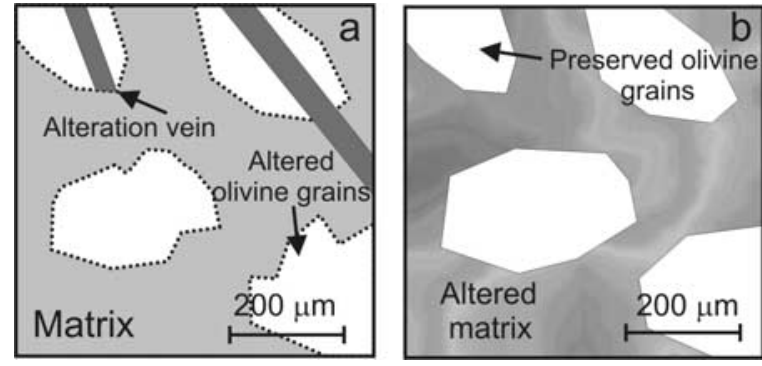

Figure 20. Schematic figure of altered olivine-rich rocks of typical grain size $>100$ microns: (a) Olivine grains are altered on their surface and through veinlets. (b) Large olivine grains are preserved, but smaller grains and the matrix are altered.

that it is uncertain whether spectral data could detect such small changes.

[58] The second type of alteration assemblage is possible because olivine grains are probably large $(>100 \mu \mathrm{m})$, as deduced from spectral analysis [Poulet et al., 2006], and favored if the matrix contains glasses more easily altered than olivine. Olivine-phyric basalts (with large grains) are common on Earth, such as in Hawaiian-type basalts, because the liquid is rich in $\mathrm{Mg} / \mathrm{Fe}$ and olivine is the first mineral to crystallize. It could also be abundant on Mars; for example, they are found in the Gusev basalt observed by MER [McSween et al., 2006] and at least in some of the Martian meteorites [e.g., Treiman et al., 1993]. This case is possible in the previous hypotheses of the olivine-rich unit formation in Nili Fossae, i.e., olivine-rich basalts [Hamilton and Christensen, 2005] or post-Isidis volcanic units [Martínez-Alonso et al., 2006]. This case is also consistent with the olivine-rich rocks being impact melt from the Isidis Basin [Mustard et al., 2007] because an impact melt would cool quickly, therefore being able to form phenocrysts of olivine with the rest of the rock being transformed into glass.

[59] Relationships between spot 1 and spots 2 and 3 can be questioned in light of these two types of alteration assemblages. On one hand, local sites of hydrothermalism would explain the presence of these signatures in local areas only, especially as in spot 3 . In that case, the explanation of altered veinlets and partial olivine grains alteration could fit the observation. On the other hand, all these spots could be the residue of the same altered horizon. This possibility implies that this unit was once much larger (spots 1 and 3 are separated by about $200 \mathrm{~km}$ ) before erosion dissected it. This geometry would be explained better by a more widespread alteration of the olivine-rich material as explained in the second hypothesis.

[60] In summary, partial alteration of mafic rocks containing large olivine grains and a matrix with a high glass fraction or local alteration by fluid circulation may explain the observations of olivine mixed with phyllosilicates. In the eventual case these signatures are interpreted as being a single alteration mineral such as Fe-rich serpentine, the alteration by fluid circulation of a preexisting olivine-rich unit is also valid.

\subsection{Toward an Understanding of the Altered Rocks in Nili Fossae}

[61] Nili Fossae is a window into the ancient crust of Mars with a diversity of mineralogy and context. Some observations suggest that alteration of material occurred at the surface, or in the near-surface, such as layered sequences or olivine-rich altered rocks (Figures 9, 15, and 16), and other observations favor exhumation or excavation of more deeply altered materials (Figures 10, 11, 12, and 15). This apparent contrast requires some additional comments regarding chronological implications and their formation by surface weathering and/or hydrothermal circulation at depth.

[62] Chronologically, phyllosilicates detected in our study are widespread only in the Noachian crust (Figure 21). If the olivine-rich unit was deposited as melt from the Isidis basinforming impact [Mustard et al., 2007], the crustal alteration predates this impact which might have formed as early as $\sim 3.96$ Ga [Werner, 2005]. Later, the olivine-rich unit itself acquired a hydration signature interpreted as partial or local alteration. The age of this alteration cannot be known due to the lack of stratigraphic correlations, but the lack of alteration on neighboring Syrtis Major plains suggests this alteration was prior to their formation. Post-Noachian aqueous alteration forming phyllosilicates is almost absent in Nili Fossae region, as on most of Mars [Poulet et al., 2005; Bibring et al., 2006]. Nevertheless, a post-Syrtis lava plain alteration at depth, such as the one caused by the hydrothermal activity of the volcanic flows, cannot be excluded if the erosion was not able to later expose these rocks at the surface. Hereafter, we first discuss the most primitive alteration, and then the alteration of olivine-rich rocks.

[63] The presence of layering could indicate surface processes: surface weathering can alter silicates into phyllosilicates and deposit them in sediments, or layers previously formed by surface processes (wind blown or ash deposits) can be altered subsequently in a surface or near surface environment. A global survey by Malin and Edgett [2000] mapped light-toned layered deposits throughout the

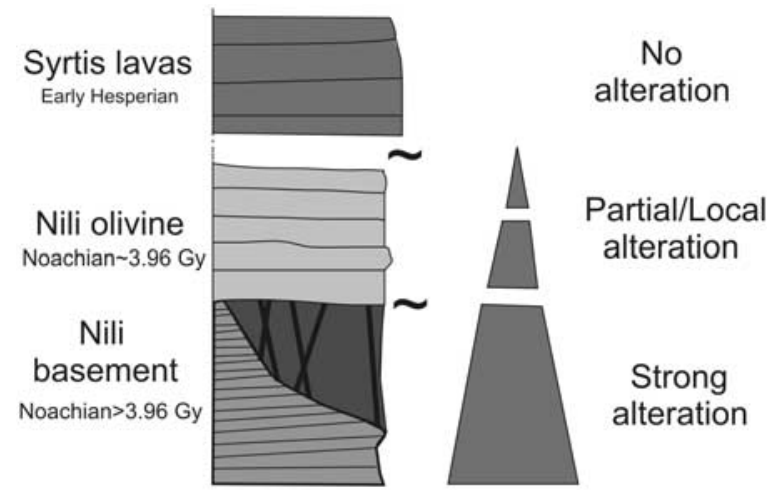

Figure 21. Simplified geologic log of units found in Nili Fossae region as well as their alteration state as deduced from OMEGA data. The basement is divided into layered units and a massive unit with locally occurrence of dikes. The decrease of alteration is seen from the local areas of altered olivine and the lack of hydrous minerals on Hesperian terrains. See text for explanations. 
whole planet. Some of these layers are visible in small outcrops at the Nili highlands-Syrtis Major Planum boundary. Malin and Edgett [2000] propose that these light-toned materials are sedimentary and common across much of the upper Martian crust. Except the layers in Figure 9, we did not find a strong correlation between the layers mapped by Malin and Edgett [2000] and phyllosilicates. Relative bright signatures of crater ejecta (Figure 11) might come from the excavation of buried layered deposits (Figure 19b), but this cannot be demonstrated. Nevertheless, the presence of layers at the Nili-Syrtis boundary is much sparse compared to other regions of the planet. By comparison, the Mawrth Valles region displays much more abundant light-toned layered rocks and associated phyllosilicates [Poulet et al., 2005; Loizeau et al., 2006]. Thus the relationships between phyllosilicates and layered terrains cannot account for all detections in the Nili Fossae region.

[64] Phyllosilicates are often observed in strongly eroded terrains (as seen from the residual buttes in Figure 10) leading to an interpretation that alteration took place in the subsurface, especially in massive terrains different from layered terrains. This material could correspond to magmatic/volcanic rocks or impact melt, altered through subsurface fluid circulation, as seen from the local presence of dikes (Figure 15) and a possible ancient volcanic cone (Figure 10e). Phyllosilicates are commonly observed spectrally in terrestrial hydrothermal areas [e.g., Hellman and Ramsey, 2004] and this is possible by different processes. Any regional magmatic activity in a water-rich crust might have generate the formation of phyllosilicates at a depth corresponding to their temperature range of formation, typically up to $300^{\circ} \mathrm{C}$ [e.g., Meunier, 2003]. One other way to trigger hydrothermal activity could be the formation of the olivinerich unit by impact melt [Mustard et al., 2007]. This process could have triggered enough heating to increase the alteration kinetics on a preexisting Martian surface buried by some tens of meters of impact melt. This process might not explain all phyllosilicate-rich areas in this region, such as those far away from Isidis (see, for example, Figure 6 of Bibring et al. [2005], located $250 \mathrm{~km}$ to the southwest), but some of the widespread signatures found stratigraphically below the olivine-rich layer (Figure 15) are possible examples. Last, some of this material could also have formed by global crustal processes due to fluid circulation in a hot crust as expected for the wholesale alteration caused by impact-related fluid circulation [e.g., Newson, 1980]. Nevertheless, the presence of phyllosilicates in only the ejecta of a few craters suggests that the crust was not altered as massively with large parts have been remained unaltered.

[65] We found that the alteration of the olivine-rich rocks can be due either to surface or subsurface alteration. If formed by surface weathering, the preservation of olivine phenocrysts during long periods is possible only if the temperatures are low (close to freezing or below). For example, preserved olivine grains in basalts from Iceland are observed after spending 9000 years at the surface [e.g., Gislason et al., 1996; Baratoux et al., 2005]. We also note that several Nakhlite meteorites display weathering by meteoric water, shown by deuterium excess of $\Delta \mathrm{D}>$ $4000 \%$ similar to the current atmosphere [Gooding et al., 1991; Watson et al., 1994]. Thus long-term exposure in a cold and arid climate, or episodic exposure, may not completely alter olivine-bearing rocks and could have preserved olivine grains. In this case, the localization of the three detected spots could correspond to residual terrains preserved from more recent mechanical erosion. Alternatively, local hydrothermalism might explain the presence of strong local signatures, not widespread on the whole olivine unit. There is no further geologic evidence, such as dikes or volcanoes that could confirm this interpretation. In both cases, the alteration of the olivine-rich unit should have been less strong that the previous basement alteration in order not to remove the olivine signature.

[66] In summary, a single type of alteration is insufficient to explain all detections. From the correlations between geology and spectral data, we can distinguish four types of phyllosilicate-rich material related to the three types of minerals detected by OMEGA:

[67] 1a. Fe-rich smectites (example in Figures 2a and 2b) correlated with surface, or near surface, smooth terrains or locally layered units, as observed in Figures 9 and 14, present over the primitive Noachian crust. This type might be similar to the outcrops found in Mawrth Valles [Loizeau et al., 2006], but it is much less significant in the Nili Fossae region.

[68] 1b. Fe-rich smectites (example in Figures 2c and 2d), correlated with massive units of the Noachian crust, locally associated with dikes and possible volcanic landforms (Figures 10 and 15), perhaps due to subsurface processes and heating, such as hydrothermal fluid circulation.

[69] These two types have similar spectra but apparently distinct geologic contexts at the current spatial sampling. Fe-rich smectites can form at different temperatures, so this correlation is not a serious discrepancy. The next-generation of spectrometers and cameras might be able to determine if these two types are distinct from their higher spatial sampling.

[70] 2. Undetermined phyllosilicates (example in Figures 2e and $2 \mathrm{f}$ ) and hydrous minerals (1.9 $\mu \mathrm{m}$ band only) found in crater ejecta (Figures 11 and 12). Hydrated ejecta likely involves the excavation of altered material in the uppermost part of the crust, but we are unable to discriminate between clay-rich sedimentary material and rocks altered hydrothermally at depth for the origin of the excavated material (Figure 19). Alteration by the impact process itself and interactions of the impact with a volatile-rich target is possible, but less plausible on the basis of our observations.

[71] 3. Olivine mixed with $\mathrm{Fe}+\mathrm{Mg}$ phyllosilicates (example in Figure 3) on a distinct unit (Figures 16 and 17) with relatively smooth texture that we interpret as a mafic rock unit altered partially at the surface or altered locally by hydrothermal activity.

\section{Conclusions}

[72] The Nili Fossae region is a window into the Martian crust. Using OMEGA spectral data together with HRSC, THEMIS and MOC images, we have examined the correlation between hydrous materials, olivine, and the main geologic units and landforms present in the Nili Fossae region. Our main conclusions are as follows:

[73] 1. At least three alteration minerals have been detected by the OMEGA spectrometer in the Nili Fossae 
region: (1) Fe-rich smectites, (2) undetermined phyllosilicates such as corrensite, vermiculite, talc or chlorite, and (3) an olivine-rich material mixed with $\mathrm{Fe}-\mathrm{OH}$ and $\mathrm{Mg}-\mathrm{OH}$ signatures such as in several phyllosilicates. Some signatures cannot be discriminated and might correspond to other hydrous minerals.

[74] 2. These minerals are observed only on the Noachian crust, in a variety of material such as layered deposits, massive exhumed materials, a dikes-rich unit, a few craters ejecta and a mafic olivine-rich unit. This diversity suggests that liquid water might have been available in significant amount to alter the crust through processes such as hydrothermalism. Surface weathering might have contributed to this alteration, but it cannot account for all detections.

[75] 3. Chronologically, most aqueous alteration occurred during the Noachian period. After the formation of the olivine-rich unit ( $\sim 3.96 \mathrm{Ga}$ if due to Isidis basin-forming impact [Mustard et al., 2007]), alteration continued but decreased in intensity and/or extent. By the time of Syrtis Major lava flows in the Hesperian period, aqueous alteration was reduced considerably, if not ceasing.

[76] 4. Fluvial and depositional landforms are poorly correlated with phyllosilicates. Their formation, subsequent to Noachian rocks rich in olivine, suggests that these landforms formed at periods during which aqueous alteration was not able to form extensive phyllosilicates. Their formation might therefore have occurred either during short periods of time, or in an arid climate, and/or under temperatures close to freezing that impeded the formation of widespread alteration minerals.

[77] 5. The presence of altered olivine-bearing rocks shows that the detection of olivine cannot be used as evidence for the absence of liquid water on early Mars. The presence of non-hydrated olivine rocks is often correlated with small scale degraded textures which appear to be the result of fresh exposure by erosion in the recent history.

[78] The next generation of high-resolution instruments on MRO will provide a better understanding of the spectral diversity as well as of the geologic complexity of the Nili Fossae crust, and provide specific geologic context for the observed alteration materials.

[79] Acknowledgments. We greatly acknowledge Sara MartínezAlonso, Vicky Hamilton, and an anonymous reviewer for their very detailed and constructive reviews. We acknowledge the effort of the OMEGA and HRSC Co-Investigator Team members and their associates who have contributed to this investigation in the preparatory phase and in scientific discussions within the teams. We acknowledge the MOC/MGS and THEMIS/Odyssey teams for the availability of their data on the respective Web pages at http://www.msss.com/mgs/moc and http://themis-data. asu.edu. French authors are granted by the Programme National de Planétologie (PNP) of Institut National des Sciences de l’Univers (INSU) and the Centre National d'Etude Spatial (CNES).

\section{References}

Abramov, O., and D. A. Kring (2003), Numerical modeling of the impactinduced hydrothermal system at Sudbury crater, Eos Trans. $A G U$, Fall Meet. Suppl., 84(46), Abstract P52A-0477.

Baratoux, D., et al. (2005), Origin and transport of volcanic sands in Iceland and implications for the evolution of volcanic material on Mars, Proc. Lunar Planet. Sci. Conf. 36th, Abstract 1603.

Baratoux, D., et al. (2006), Toward a 3-D view of the mineralogy of Syrtis Major through impact cratering from OMEGA data, Proc. Lunar Planet. Sci. Conf. 37th, Abstract 1376.

Bibring, J.-P., et al. (2005), Mars surface diversity as revealed by the OMEGA/Mars Express observations, Science, 307, 1576-1581.
Bibring, J.-P., Y. Langevin, J. F. Mustard, F. Poulet, R. Arvidson, A. Gendrin, B. Gondet, N. Mangold, P. Pinet, and F. Forget (2006), Global mineralogical and aqueous Mars history derived from the OMEGA/ Mars Express data, Science, 312, 400-404.

Borg, L., and M. J. Drake (2005), A review of meteorite evidence for the timing of magmatism and of surface or near-surface liquid water on Mars, J. Geophys. Res., 110, E12S03, doi:10.1029/2005JE002402.

Browning, L., G. J. Taylor, and D. Pickett (2003), Minimum times to form clay in Martian surface and near-surface environments, Proc. Lunar Planet. Sci. Conf. 34th, Abstract 1708.

Chesworth, W., J. Dejou, P. Larroque, and E. G. Rodeja (2004), Alteration of olivine in a basalt from central France, Catena, 56, 21-30.

Christensen, P. R., et al. (2001), Mars Global Surveyor Thermal Emission Spectrometer experiment: Investigation description and surface science results, J. Geophys. Res., 106(E10), 23,823-23,872.

Christensen, P. R., et al. (2003), Morphology and composition of the surface of Mars: Mars Odyssey THEMIS results, Science, 300, 2056-2061.

Clark, R. N., G. A. Swayze, A. Gallagher, T. V. V. King, and W. M. Calvin (1993), The USGS Digital Spectral Library, U.S. Geol. Surv. Open File Rep., 93-592, 1340 pp. (Available at http://speclab.cr.usgs.gov)

Costard, F., F. Poulet, J.-P. Bibring, D. Baratoux, N. Mangold, S. Meresse, P. Pinet, and OMEGA Team (2006), Detection of hydrated minerals on fluidized ejecta lobes from OMEGA observations: Implications for the history of Mars, Proc. Lunar Planet. Sci. Conf. 37th, Abstract 1288.

Fassett, C. I., and J. W. Head III (2005), Fluvial sedimentary deposits on Mars: Ancient deltas in a crater lake in the Nili Fossae region, Geophys. Res. Lett., 32, L14201, doi:10.1029/2005GL023456.

Gendrin, A., et al. (2005), Sulfates in Martian layered terrains: The OMEGA/Mars Express view, Science, 307, 1587-1591.

Gillet, P., J. A. Barrat, E. Deloule, M. Wadhwa, A. Jambon, V. Sautter, B. Devouard, D. Neuville, K. Benzerara, and M. Lesourd (2002), Aqueous alteration in the northwest Africa 817(NWA817) Martian meteorite, Earth Planet. Sci. Lett., 203, 431-444.

Gillot, F., D. Righi, and M. L. Räisänen (1999), Formation of smectites and their alteration in two chronosequences of podzols in Finland, in Clays to Our Future: Proceedings of the 11th International Clay Conference, Ottawa, edited by H. Kodama, A. R. Mermut, and J. K. Torrance, pp. 725-731, ICC97 Organizing Comm., Ottawa, Canada.

Gislason, S. R., and S. Arnorsson (1993), Dissolution of primary basaltic minerals in natural waters: Saturation state and kinetics, Chem. Geol., $105,117-135$.

Gislason, S. R., S. Arnorsson, and H. Armannsson (1996), Chemical weathering of basalt in SW Iceland: Effects of runoff, age of rocks and vegetative/glacial cover, Am. J. Sci., 296, 837-907.

Gooding, J. L., S. J. Wentworth, and M. E. Zolensky (1991), Aqueous alteration in the Nakhla meteorite, Meteoritics, 10, 317-324.

Greeley, R., and J. E. Guest (1987), Geologic map of the eastern equatorial region of Mars, U.S. Geol. Surv. Invest. Ser., Map I-1802B.

Güven, N. (1988), Smectite, in Hydrous Phyllosilicates, Rev. Mineral., vol. 19, edited by S. W. Bailey, pp. 497-522, Mineral. Soc. of Am., Washington, D. C.

Gwinner, K., F. Scholten, B. Giese, J. Oberst, R. Jaumann, M. Spiegel, R. Schmidt, and G. Neukum (2005), Hochauflösende Digitale Geländemodelle der Marsoberfläche auf der Grundlage von Mars Express HRSC Daten, Photogramm. Fernerkundung Geoinf., 5, 387-394.

Hamilton, V. E., and P. R. Christensen (2005), Evidence for extensive, olivine-rich bedrock on Mars, Geology, 33(6), 433-436.

Hellman, M. J., and M. S. Ramsey (2004), Analysis of hot springs and associated deposits in Yellowstone National Park using ASTER and AVIRIS remote sensing, J. Volcanol. Geotherm. Res., 135, 195-219.

Hiesinger, H., and J. W. Head III (2004), The Syrtis Major volcanic province, Mars: Synthesis from Mars Global Surveyor data, J. Geophys. Res., 109, E01004, doi:10.1029/2003JE002143.

Hoefen, T. M., R. N. Clark, J. L. Bandfield, M. D. Smith, J. C. Pearl, and P. R. Christensen (2003), Discovery of olivine in the Nili Fossae region of Mars, Science, 302, 627-630.

Irwin, R. P., III, A. D. Howard, R. A. Craddock, and J. M. Moore (2005), An intense terminal epoch of widespread fluvial activity on early Mars: 2. Increased runoff and paleolake development, J. Geophys. Res., 110, E12S15, doi:10.1029/2005JE002460.

Jouglet, D., F. Poulet, J. Mustard, R. Milliken, J.-P. Bibring, Y. Langevin, and B. Gondet (2007), Observation of the $3 \mu \mathrm{m}$ hydration feature on Mars from OMEGA/Mars Express data, J. Geophys. Res., doi:10.1029/ 2006JE002846, in press.

Kraal, E. R., M. P. Wong, E. B. Grosfils, M. S. Gilmore, S. J. Kozak, and L. A. Reinen (1998), The origin and modification of a trough in the Nili Fossae, Mars, Lunar Planet. Sci., XXIX, Abstract 1130.

Laity, J. E., and M. C. Malin (1985), Sapping processes and the development of theater headed valley networks on the Colorado Plateau:, Geol. Soc. Am. Bull., 94(2), 203-217. 
Loizeau, D., et al. (2006), Phyllosilicates rich terrains in Mawrth Vallis region, Mars, as seen by OMEGA and HRSC/Mars Express, Proc. Lunar Planet. Sci. Conf. 37th, Abstract 1658.

Malin, M. C., and K. S. Edgett (2000), Sedimentary rocks of early Mars, Science, 290, 1927-1937.

Malin, M. C., and K. S. Edgett (2001), Mars Global Surveyor Mars Orbiter Camera: Interplanetary cruise through primary mission, J. Geophys. Res., 106(E10), 23,429-23,570.

Mangold, N. (2005), High latitude patterned ground on Mars: Classification, distribution and climatic control, Icarus, 174(2), 336-359.

Mangold, N., and V. Ansan (2006), Detailed study of an hydrological system of valleys, a delta and lakes in Thaumasia region, Mars, Icarus, $180,75-87$

Mangold, N., V. Ansan, D. Baratoux, P. Masson, and G. Neukum (2006a), Identification of a new outflow channel on Mars in Syrtis Major region, Proc. Lunar Planet. Sci. Conf. 37th, Abstract 1802.

Mangold, N., et al. (2006b), Correlation between phyllosilicates, olivine and landforms in Nili Fossae region, Mars, Proc. Lunar Planet. Sci. Conf 37th, Abstract 1791.

Martínez-Alonso, S., M. T. Mellon, B. C. Kindel, and B. M. Jakosky (2006), Mapping compositional diversity on the surface of Mars: The Spectral Variance Index, J. Geophys. Res., 111, E01004, doi:10.1029/ 2005JE002492.

McSween, H. Y., et al. (2006), Characterization and petrologic interpretation of olivine-rich basalts at Gusev Crater, Mars, J. Geophys. Res., 111, E02S10, doi:10.1029/2005JE002477.

Melosh, H. J. (1989), Impact Cratering: A Geologic Process, 248 pp., Oxford Univ Press, New York.

Meunier, A. (2003), Argiles, 436 pp., Gordon and Breach Sci., New York.

Milliken, R. E., and J. F. Mustard (2005), Quantifying absolute water content of minerals using near-infrared reflectance spectroscopy, J. Geophys. Res., 110, E12001, doi:10.1029/2005JE002534.

Moore, J. M., and A. D. Howard (2005), Large alluvial fans on Mars, J. Geophys. Res., 110, E04005, doi:10.1029/2004JE002352.

Mustard, J. F., F. Poulet, A. Gendrin, J.-P. Bibring, Y. Langevin, B. Gondet, N. Mangold, G. Bellucci, and F. Altieri (2005), Olivine and pyroxene diversity in the crust of Mars, Science, 307, 1594-1597.

Mustard, J. F., F. Poulet, J. W. Head, N. Mangold, J.-P. Bibring, S. M. Pelkey, C. I. Fassett, Y. Langevin, and G. Neukum (2007), Mineralogy of the Nili Fossae region with OMEGA/Mars Express data: 1. Ancient impact melt in the Isidis Basin and implications for the transition from the Noachian to Hesperian, J. Geophys. Res., 112, E08S03, doi:10.1029/2006JE002834

Newson, H. E. (1980), Hydrothermal alteration of impact melt sheets with implications for Mars, Icarus, 44, 207-216.

Poulet, F., J.-P. Bibring, J. F. Mustard, A. Gendrin, N. Mangold, Y. Langevin, R. E. Arvidson, B. Gondet, and C. Gomez (2005), Phyllosilicates on Mars and implications for early Martian climate, Nature, 438, 623-627.

Poulet, F., J. F. Mustard, J.-P. Bibring, A. Gendrin, P. Pinet, Y. Langevin, and S. Le Mouelic (2006), A comparative analysis of the ancient crust and volcanic regions of Mars using OMEGA-MEx data: Deconvolution of spectra using nonlinear spectral mixing, paper presented at EGU 3rd General Assembly, 2-7 April, Eur. Geosci. Union, Vienna.

Poulet, F., C. Gomez, J.-P. Bibring, Y. Langevin, B. Gondet, P. Pinet, G. Belluci, and J. Mustard (2007), Martian surface mineralogy from Observatoire pour la Minéralogie, l'Eau, les Glaces et l'Activité on board the Mars Express spacecraft (OMEGA/MEx): Global mineral maps, J. Geophys. Res., 112, E08S02, doi:10.1029/2006JE002840.

Righi, D., and A. Meunier (1995), Origin of clays by rock weathering and soil formation, in Origin and Mineralogy of Clays, edited by B. Velde, pp. 43-161, Springer, Berlin

Righi, D., K. Huber, and C. Keller (1999), Clay formation and podzol development from postglacial moraines in Switzerland, Clays Clay Miner., 34, 319-332.

Schaber, G. G. (1982), Syrtis major: A low-relief volcanic shield, J. Geophys. Res., 87, 9852-9866.

Thordarson, T., and G. Larsen (2006), Volcanism in Iceland in historical time: Volcano types, eruption styles and eruptive history, J. Geodyn., 43, 118-152, doi:10.1016/j.jog.2006.09.005

Treiman, A. H., and D. J. Lindstrom (1997), Trace element geochemistry of Martian iddingsite in the Lafayette meteorite, J. Geophys. Res., 102, $9153-9163$

Treiman, A. H., R. A. Barett, and J. L. Gooding (1993), Preterrestrial aqueous alteration of the Lafayette meteorite, Meteoritics, 28, 86-97.

Velde, B., D. Righi, A. Meunier, S. Hillier, and A. Inoue (1995), Origin of clays by rock weathering and soil formation, in Origin and Mineralogy of Clays, edited by B. Velde, pp. 43-157, Springer, Berlin.

Watson, L. L., I. D. Hutcheon, S. Epstein, and E. M. Stolper (1994), Water on Mars: Clues from $\mathrm{D} / \mathrm{H}$ and water contents of hydrous phases in $\mathrm{SNC}$ meteorites, Science, 265, 86-90.

Werner, S. C. (2005), Major aspects of the chrono-stratigraphy and geologic evolutionary history of Mars, Ph.D. dissertation, Cuvilier, Berlin.

Wichman, R. W., and P. H. Schultz (1989), Sequence and mechanisms of deformation around the Hellas and Isidis impact basins on Mars, J. Geophys. Res., 94(B12), 17,333-17,357.

V. Ansan, N. Mangold, and Ph. Masson, Laboratoire IDES, UMR8148 CNRS and Université Paris-Sud, Bâtiment 509, F-91405 Orsay Cedex, France. (nicolas.mangold@u-psud.fr)

J.-P. Bibring, B. Gondet, Y. Langevin, and F. Poulet, Institut d'Astrophysique Spatiale, CNRS/Université Paris Sud, Bâtiment 120, F-91405 Orsay, France.

C. Fassett, J. W. Head III, and J. F. Mustard, Department of Geological Sciences, Brown University, Box 1846, Providence, RI 02912, USA.

H. Hoffmann, Institut für Weltraumsensorik, DLR, D-12489 Berlin, Germany.

G. Neukum, Institut für Geologische Wissenschaften, Freie Universität Berlin, D-12489 Berlin, Germany. 